
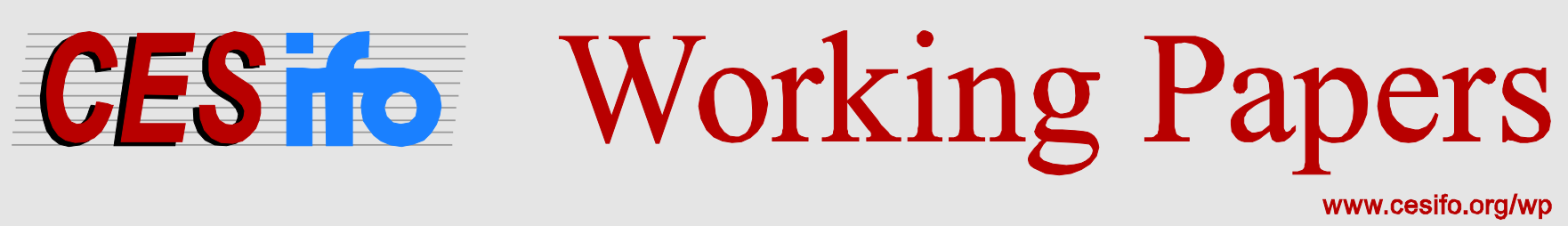

\title{
What Drives Aggregate Investment? Evidence from German Survey Data
}

\author{
Rüdiger Bachmann \\ Peter Zorn
}

\author{
CESIFO WORKING PAPER NO. 4218 \\ CATEgory 6: Fiscal Policy, Macroeconomics and GROWTH \\ ORIGINAL VERSION: APRIL 2013 \\ THIS VERSION: FEBRUARY 2018
}

An electronic version of the paper may be downloaded

- from the SSRN website:

- from the RePEc website:

- from the CESifo website:

WWw.SSRN.com

www.RePEc.org

www.CESifo-group.org/wp

\section{CESifo}




\title{
What Drives Aggregate Investment? Evidence from German Survey Data
}

\begin{abstract}
The ifo Investment Survey asks firms in the German manufacturing sector about the importance of sales, technological factors, finance, return expectations, and macroeconomic policy for their investment activity in a given year. We show that these subjective investment determinants 1) capture economically what their labels suggest, and 2) have strong explanatory power for aggregate manufacturing investment growth fluctuations. In a second step, we use these determinants to identify aggregate demand and aggregate technology shocks and argue that the bulk of the variance of both aggregate manufacturing investment and output growth fluctuations (as much as approximately two thirds in both cases) is explained by aggregate demand shocks. Consistent with neoclassical views, however, technological factors are the most important investment determinant on average.
\end{abstract}

JEL-Code: D900, D910, E200, E220, E300, E320.

Keywords: investment dynamics, investment determinants, survey data, narrative approach, aggregate demand shocks, sentiment shocks.

\author{
Rüdiger Bachmann \\ University of Notre Dame \\ Department of Economics \\ USA - 46556 Notre Dame IN \\ rbachmann@nd.edu
}

\author{
Peter Zorn* \\ University of Munich \\ Department of Economics \\ Germany - 80539 Munich \\ zorn@econ.Imu.de
}

*corresponding author

February 9, 2018

We are grateful to George-Marios Angeletos, our discussants James Kahn, Michael MacMahon, and Malte Rengel, and conference/seminar participants at the ifo Macro Seminar, the 2012 ifo Conference on "Macroeconomics and Survey Data", Boston University, the $11^{\text {th }}$ New York/Philadelphia Workshop on Quantitative Macroeconomics at Yeshiva University, the 2013 Doctoral Workshop on Dynamic Macroeconomics in Konstanz, the 2013 Spring Meeting of Young Economists in Aarhus, the University of Munich, the 2013 EEA Meeting in Gothenburg, the Cleveland FED, the 2014 ASSA Meetings in Philadelphia, the European Summer Symposium in International Macroeconomics in Tarragona, the Frankfurt Money and Macro Brown Bag Seminar, the 2015 SED conference in Warsaw, the 2015 Meeting of the German Economic Association's macroeconomics committee, the IfW Kiel, and the 2016 Arizona State University Conference on "New Data and New Questions: Implications for Macroeconomics", for their useful comments and suggestions. We also thank Annette Weichselberger from the ifo institute for helping us with the data and giving us background information about the survey. 


\section{Introduction}

What drives aggregate fluctuations? This is a seminal question in macroeconomics (see Kocherlakota, 2009), to which a number of approaches have been brought to bear: structural vector autoregressions (to cite only a few seminal papers: Blanchard and Quah, 1989. Christiano et al. 1996, Blanchard and Perotti, 2002); dynamic factor models (e.g., Stock and Watson (2012)); estimated DSGE models (e.g., Smets and Wouters (2007)); business cycle accounting (e.g., Chari et al. (2007)); and narrative approaches to identifying macroeconomic policy shocks, possibly in conjunction with structural vector autoregressions (see, for example, Romer and Romer, 2004, 2010, Mertens and Ravn, 2013) 11

This paper pursues a novel and complementary approach, using unique firm-level data from the Munich-based ifo Investment Survey (IS). The IS asks decision makers in German manufacturing firms about the importance of sales, technological factors, finance, return expectations, and macroeconomic policy as determinants for their investment activity in a given year. We propose a survey-based, narrative approach that estimates shocks from this subjective reasons data, including shocks potentially unrelated to macroeconomic policy. The approach in the literature closest in spirit to ours is Bewley (1999), who interviews managers in firms to investigate the sources of downward nominal wage rigidity. Using the firm-level survey responses, we first construct index measures of the importance of each investment determinant in the manufacturing sector (henceforth called aggregate investment determinant indices). In a second step, we recover orthogonal aggregate shocks from these index series. We finally compute the contributions of the identified aggregate shocks to the fluctuations of aggregate manufacturing investment growth (henceforth aggregate investment growth).

We argue that, in Germany, aggregate demand shocks and aggregate technology shocks shocks are the only plausible candidates for explaining aggregate investment fluctuations ${ }^{2}$

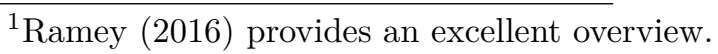

${ }^{2}$ In this sense, our findings are related to Blanchard and Quah (1989)'s seminal contribution, although we show this bipartition as a result rather than imposing it as an assumption.
} 
and make them therefore the main focus of our strategy to identify orthogonal aggregate shocks from the narrative determinant series. To disentangle these two shocks in the data, we impose correlation restrictions that rely on the informational content of the narrative series and simple economic theory ${ }^{3}$ Specifically, we require that the identified aggregate demand shocks are highly correlated with the sales investment determinant, and likewise for the identified aggregate technology shocks and the technological factors investment determinant. In addition, in many standard models aggregate demand shocks and aggregate technology shocks have different implications for prices. In particular, producer price inflation should be positively correlated with aggregate demand shocks while its correlation with technology shocks should be negative, and we impose these implications for identification.

We find that, consistent with neoclassical views, on average over time technological factors are the most important investment determinant. This is not the case for the fluctuations of aggregate investment growth (and also of aggregate output growth). First, a considerable portion, 81 percent, of the total variance of aggregate investment growth can be explained by our survey-based subjective investment determinants and the orthogonal shocks extracted from them. This result shows the high quality of these survey data, and, more generally, lends credence to our survey-based narrative approach. Second, in our baseline identification scheme, we find that approximately two thirds of the total variance of aggregate investment growth can be explained through aggregate demand shocks. Aggregate technology shocks play only a minor role 4 This finding is also confirmed in a counterfactual simulation of the post-reunification German aggregate investment rate: almost none of the officially declared recession years for Germany would have experienced negative investment growth without the aggregate demand shocks, in contrast to the data. The reunification boom would not exist, neither would the prolonged slump in the early 2000s. There would have been no invest-

\footnotetext{
${ }^{3}$ See also Ludvigson et al. (2017a b) who advocate for new identification techniques for structural vector autoregressions by imposing correlation restrictions.

${ }^{4}$ In contrast to a large part of the literature, our approach allows us to jointly identify aggregate demand and aggregate technology shocks. In other identification schemes, where we disregard the correlation restrictions with producer price inflation, technology shocks contribute no more than 30 percent to the total variance of aggregate investment growth.
} 
ment boom nor a rebound around the Great Recession. In other words, without aggregate demand shocks, the aggregate investment growth rate series would not align with the German post-reunification business cycle. Aggregate demand shocks are thus essential for our understanding of this business cycle.

What are these aggregate demand shocks that we identify as determining the bulk of aggregate investment fluctuations? In this paper, we provide a negative and a positive answer to this question.

First, using industry-specific capital expenditure and subjective investment determinant data and input-output matrices for the German manufacturing sector, we argue that our identified aggregate demand shocks are unlikely to be the result of misclassification of industryspecific technology shocks that spill over to other industries where they are merely perceived as demand shocks: for instance, one small manufacturing industry which procures large amounts of input goods from other upstream manufacturing industries could have a positive technology shock followed by increased input demand for other manufacturing industries, which would lead to higher demand-related investment there. Alternatively, consider a large manufacturing industry that makes an invention that is sold to downstream industries. It might classify a technological shock as increased demand for its products. We investigate both channels and conclude that none appears quantitatively relevant. Moreover, an industry-level analysis shows that in most manufacturing industries the aggregate pattern - demand shocks explain the bulk of investment growth volatility - replicates itself at the more disaggregate level, that is, our aggregate results are not a mere composition effect.

Second, we use manufacturing business sentiment and consumer sentiment data to argue that our identified aggregate demand shocks, which correlate well with these standard sentiment measures, are good candidates for sentiment or animal spirit shocks. By contrast, with the one and clear exception of the post-reunification monetary tightening in Germany by the Bundesbank and the immediate subsequent recovery, no obvious demand stabilization policy instrument has any association with our identified aggregate demand shocks. 
Traditionally, there has been a branch of economics methodology that viewed subjective survey approaches, that is, asking economic agents what they did, what they expect and why they did something, with some scepticism. Nevertheless, a growing number of economists has now made use of subjective survey data, mainly to study expectation formation and their rationality: Nerlove (1983), using business surveys from various countries, is a very early example, Bachmann and Elstner (2015) and Gennaioli et al. (2015) are more recent ones. Guiso and Parigi (1999), Bachmann et al. (2013) and Bachmann et al. (2017) have used expectation data from business surveys to study the impact of business uncertainty on economic activity. On the household side, Carroll and Dunn (1997), Souleles (2004), Bachmann et al. (2015) and Malmendier and Nagel (2016) are important examples, each with different research questions.

We view our approach as pushing one step further: if we can ask economic agents about their subjective expectations and gain useful economic insights, why not ask them about their subjective reasons for carrying out a particular economic action and use the answers for economic analysis?5 The advantage of our survey-based approach towards identifying shocks lies in this putative directness: the survey respondents report whether their investment activity in a given year was influenced by, for instance, technological factors, and, if so, how strongly. As a result, the narrative series constructed from the survey responses and used in shock identification are less prone to be confounded by other factors. In this regard, our approach is similar to other narrative methodologies that have been used in empirical macroeconomics to study the effects of macroeconomic policies (see Romer and Romer, 2004.

\footnotetext{
${ }^{5}$ For example, some of the disagreement in the literature about the importance of technology shocks results from measurement issues: because of their unobserved nature, macroeconomists have to resort to various empirical approaches to measure them, each with its underlying assumptions that can be the target of critique. For example, the "purified" technology measure by Basu et al. (2006) - basically the Solow residual accounting for non-technological effects such as varying capacity utilization, non-constant returns to scale, and aggregation effects - might be prone to "incomplete cleansing"; see Alexopoulos (2011, p.1146). The other often-used technology measure, obtained from long-run restrictions in vector autoregressions, can be contaminated by other, possibly also unobserved, exogenous shocks, for example tax shocks or preference shocks, or made invalid by heterogeneous factor inputs into the aggregate production function; see, respectively, Uhlig (2004) and Bocola et al. (2014). We do not claim to have found a silver bullet in this paper, but at least the narrative directness of our approach in conjunction with it passing many plausibility checks in the micro and the macro data provides a new perspective on the problem.
} 
2010). Indeed, before we use the reasons data for shock extraction, one of the contributions of this paper is to show extensively that the investment determinants that we base our narrative approach on have highly plausible economic content: the sales investment determinant is highly correlated with new manufacturing orders; the technological investment determinant is correlated with the prevalence of restructuring and rationalization investment as well as process innovations carried out at the firm level; and the finance investment determinant is related to independent measures of external finance dependence at the firm level, and, in the time series, to credit spreads and proxies of idiosyncratic business uncertainty. Finally, we show that firms for which the sales determinant is important for their investment behavior, are more likely to increase prices and less likely to decrease them; and vice versa for the technological determinant.

The remainder of this paper is organized as follows. Section 2 introduces the survey data and presents the aggregate investment determinant indices. We also validate in great detail the survey data against proxy variables for aggregate demand, technology, etc. Section 3 lays out the empirical model for estimating the contribution of the aggregate investment determinants to aggregate investment growth fluctuations, and motivates the identifying assumptions. Section 4 presents the results, both for the manufacturing sector and disaggregated at the two-digit industry level and by German states. Section 5 summarizes the main findings and concludes.

\section{The Survey Data}

\subsection{The ifo Investment Survey (IS)}

The IS is a semi-annual survey for the German manufacturing sector ${ }^{6}$ carried out in the spring and fall by the ifo Institute since 1955. Its main purpose is to provide firm-level quantitative capital expenditure data and future investment plans for a panel of firms. In addition,

\footnotetext{
${ }^{6}$ The mining sector is also included, though it is very small relative to manufacturing proper.
} 
since 1989 the fall survey questionnaire asks firms about the qualitative and subjective effects of several investment determinants on their capital expenditures in the current year, a rather unique feature of this survey. We have access to the micro data to perform our analysis until 2013.7 We only use the West German part of the data, because the survey questionnaire for East German firms is different and much less consistent over the years compared to that for West German firms.

The main advantages of the IS are its high number of respondents, counting on average roughly 1,600 firms per year in our sample; that it provides quantitative firm-specific capital expenditure data; and the information about qualitative and subjective investment determinants, along with a host of other information about firm-level investment activities that we use to cross-validate the content of the subjective investment determinants. In addition, we can merge a subset of firms from the IS with another prominent ifo Institute firm survey, the ifo Business Cycle Survey, which we will also use for cross-validation. Moreover, aggregate investment growth based on the survey micro data is highly correlated (0.89) with manufacturing investment growth data from the Federal Statistical Office (see Figure 1), which means that our sample is representative of the business cycle behavior of the universe of firms in the German manufacturing sector.8 The low annual frequency of the data and the relatively small number of observations, thus available in the time dimension, a time series of 25 , is admittedly a disadvantage.$^{9}$ Nevertheless, we note that the planning horizon of firms for investment typically spans a (fiscal) year, so the annual frequency of the data is not per se restrictive.

Specifically, we make use of the following two questions from the survey questionnaire:

\footnotetext{
${ }^{7}$ Confidentiality agreements with the firms cause a certain delay as to when the micro data are available to researchers.

${ }^{8}$ We note that this high correlation is not a mechanical result, as the IS data is not an input into the official investment numbers. National accounting investment data are based on a separate and administrative investment survey run by the Federal Statistical Office, which does not ask about investment determinants.

${ }^{9}$ Our robustness checks using semi-aggregate data at the two-digit industry level and by German Laender mitigate this problem somewhat.
} 


\section{Q1. Gross Fixed Capital Formation in Fiscal Year [Last Year]}

[Last Year]

$$
\text { (in } 1000 \text { Euro) }
$$

\section{Q2. Investment Determinants [This Year]}

Our investment activity in the Old Laender in [This Year] was positively/negatively affected by:

Investment Determinant
$\begin{aligned} & \text { [This Year] } \\ & \text { positive } \\ & \text { influence }\end{aligned}$ $\begin{gathered}\text { positive } \\ \text { influence }\end{gathered}$

In Q1 firms report their realized capital expenditures for the preceding year, which is asked in the spring and the fall surveys (except for the falls of 2002 and 2003). In Q2, which is asked only in the fall survey, firms give information about how several investment determinants have affected their investment activity in the current year. Specifically, the survey questionnaire asks firms about the effects of their sales situation and expectations, finance, return expectations, technological factors, the macro policy environment, and other investment determinants on their capital expenditures 10 The possible answers are: "strongly negative", "weakly negative", "no influence", "weakly positive", or "strongly positive". The respondent is asked to check one box for each investment determinant. We code the answers in the variables Tech, Finance, Sales, Return, Macro, and Other that can take on the values -2 (strongly negative influence), -1 (weakly negative influence), 0 (no influence), +1 (weakly positive influence), or +2 (strongly positive influence) 11

We only consider firm-year observations where the investment growth rate and at least

\footnotetext{
${ }^{10}$ The survey guidelines for the investment determinants are available in the appendix.

${ }^{11}$ The main results are quantitatively very similar if we use a concave (square root) or convex (quadratic) quantification scheme instead.
} 
one investment determinant are observable. Of course, we sync the answers to Q1 and Q2 in such a way that the investment determinants of a given year are paired with the investment activity of that same year. Our sample is based on 40,905 firm-year observations in total.

\section{$2.2 \quad$ Aggregation}

Recall that our research question is about the sources of fluctuations in aggregate (manufacturing) investment growth. To quantify these sources, we first aggregate, separately for each investment determinant, the survey responses through weighted averaging to compute what we call aggregate investment determinants, which are thus meant to capture the aggregate importance of a particular reason to invest in a given year. From these investment determinants we later recover orthogonal aggregate shocks ${ }^{12}$ The fundamental identification assumption of our survey-based narrative approach is that the firm-level survey responses contain information about the shocks that affect firms' investment decisions. The putative advantage of the survey-based approach is that the macroeconomic shocks are ultimately extracted from variables which are meant to directly measure the effect of, say, technology on capital expenditures.

In extensions, we also study semi-aggregate specifications at the two-digit industry level, and at the German Laender (German states) level, allowing us to gauge whether our aggregate results are driven by particular groups of firms or whether they capture aggregate phenomena. We find the latter.

Formally, let $\Delta I_{t}^{I F O}$ denote aggregate investment growth based on Q1 of the IS, invit is firm $i$ 's investment in year $t, 13$ and $N_{t}$ is the number of observations for which firm-level

\footnotetext{
${ }^{12}$ Our approach is thus related to structural factor-analytic methods; see Stock and Watson (2016) for a recent survey. In particular, the aggregate investment determinant indices can be interpreted as what Stock and Watson (2016) call named factors, i.e., they are linked to a specific reason to invest, estimated by cross-sectional averaging, which is a simple example of nonparametric estimation of factor models. We then identify orthogonal structural shocks from these factors.

${ }^{13}$ We average the fall and the spring capital expenditure data, whenever they are both available, because in a few circumstances they may slightly deviate from each other, and averaging thus helps mitigate measurement and reporting error. Otherwise we use whichever investment number, spring or fall, is available. The results are robust to using only the fall data. See for a detailed discussion of both data treatment procedures Bachmann et al. (2017).
} 
data is observable in years $t$ and $t-1$. Define firm $i$ 's share in total investment at time $t$ by $\omega_{i t}=\frac{i n v_{i t}}{\sum_{i=1}^{N_{t}} i n v_{i t}}$. Then the aggregate investment growth rate, $\Delta I_{t}^{I F O}$, is given by:

$$
\Delta I_{t}^{I F O}=\sum_{i=1}^{N_{t}} \omega_{i t-1} \frac{i n v_{i t}-i n v_{i t-1}}{i n v_{i t-1}}
$$

Similarly, let $x_{i t}$ denote any of the six firm-level investment determinants defined above, ranging from -2 to +2 . Then, for every investment determinant, we aggregate up to an investment determinant index, $X_{t}$, as follows:

$$
X_{t}=\sum_{i=1}^{N_{t}} \omega_{i t} x_{i t}
$$

With a slight abuse of notation, Tech, Finance, Sales, Return, Macro, and Other may henceforth refer also to these aggregate investment determinant indices.

\subsection{The Raw Data}

In Figure 1, we compare the aggregate investment growth rate obtained from the Ifo Investment Survey data, $\Delta I_{t}^{I F O}$, with that obtained from data for the West German manufacturing sector provided by the Federal Statistical Office, $\Delta I_{t}^{F S O}$. The correlation coefficient between both series is 0.89 .

Figure 2 plots the aggregate investment determinant indices over time. Two observations in Figure 2 stand out. First, in contrast to the other investment determinant indices which often fluctuate around zero, the effect of technology on capital expenditures is positive throughout. In fact, as panel $\mathrm{C}$ of Table 1 shows, technological factors are on average the most important subjective investment determinant. This observation is consistent with the neoclassical view that technological factors determine investment on average and in the longrun: the average value of Tech is 0.92 , followed by Sales, which averages 0.60. By contrast, Finance and Macro are essentially zero on average. 
Second, the aggregate investment determinant indices are (imperfectly) correlated with each other and the business cycle. Panel A of Table 1 shows the pairwise correlation coefficients of the investment determinants in the sample. For statistical inference, we generate 10,000 bootstrap estimates for the correlation coefficients by resampling overlapping moving blocks of a three-year length from the data. Next, to gauge statistical significance, we compute the fraction of bootstrap samples for which the correlation coefficient has the opposite sign of the point estimate. The correlation between Sales, Tech, Finance, Return and Macro is always significant, positive, and in one case substantial: Sales and Return have a correlation coefficient of approximately 0.95 , which suggests that both variables capture essentially the same economic concept, and that Return, that is, a firm's return on investment, is viewed by the firms as mostly Sales-determined. The investment determinant index Other is not significantly correlated with any of the other variables.

The fact that some of these aggregated investment determinants are correlated is not surprising: for example, a shock to financial intermediation in the economy may impact investment directly through standard finance effects, but also simultaneously through an aggregate demand effect from other firms and the households in this economy. It means, however, that we cannot interpret the investment determinants directly as shocks (hence the use of "investment determinants"). Nevertheless, we will argue below that given the investment determinant's economic content, which we will explicate in the next subsection, and because of, in many standard models, differential implications of demand and technology shocks for prices, we can extract from these investment determinants orthogonal shocks that can be interpreted as aggregate demand and aggregate technology shocks.

Panel B of Table 1 reports the correlations of the investment determinant indices with the aggregate investment growth rate, $\Delta I_{t}^{F S O}$. The correlation with Sales, Finance, Return and Macro, is significant and strong in general. For example, the correlation coefficient between Sales and $\Delta I_{t}^{F S O}$ is 0.84 . The correlation coefficient between Tech and $\Delta I_{t}^{F S O}$ is also significant, but clearly lower at 0.55 . The category Other is not significantly correlated 
with the aggregate investment growth rate.14

From this simple correlational analysis we may already expect that technology shocks might be not the main source of time series variation in aggregate investment growth. This hypothesis is also supported by the volatilities of these investment determinants: Sales and Return are very volatile, unlike Tech, Finance and Macro. As we have seen, the latter two also have little importance as investment determinants on average, which together means that we can expect them to play only a minor role in explaining aggregate investment fluctuations in Germany.

To sum up, this simple statistical analysis already reveals many results that we later find confirmed in our econometric analysis: Sales and Return are very volatile and highly correlated with investment growth (and with each other, which means they capture the same economic concept); given its mean, Tech is important for investment on average, but given its relatively low volatility and milder correlation with aggregate investment growth unlikely its major driver; Finance and Macro with their low means and low volatilities are not likely to be important for aggregate investment in Germany; and Other with its lack of correlation with either aggregate investment or any other investment determinant is an orthogonal catch-all category, again unlikely to be important for aggregate investment. These findings suggest we can treat Sales and Tech as the core of our analysis, and they justify our focus later on aggregate demand versus aggregate technology shocks.

We conclude this section by separately investigating the behavior of the fraction of survey responses for each of the five answer categories - "strongly negative", "weakly negative", "no influence", "weakly positive", or "strongly positive" - and each of the six investment determinants: Sales, Tech, Finance, Return, Macro, and Other (here referring to the firm-

\footnotetext{
${ }^{14} \mathrm{All}$ these results are very similar with $\Delta I_{t}^{I F O}$. Also, to provide some perspective on the business cycle properties of aggregate investment growth in our sample, 1989-2013, vis-à-vis a larger sample from 1965-2013: volatility is somewhat smaller in our baseline sample (0.0943) versus the larger sample (0.1076); the first-order autocorrelation is 0.26 for the 1989-2013 sample, and 0.32 for the 1965-2013 sample; the correlation with manufacturing industrial production growth is 0.70 (1989-2013 sample) versus 0.59 (1965-2013 sample); and the relative volatility to manufacturing industrial production growth is 1.66 (1989-2013 sample) versus 2.13 (1965-2013 sample). Overall, the German business cycle is reasonably stable even across the reunification so that our analysis is not specific to the post-reunification era.
} 
level survey responses), as shown in Figure 3. The modal responses for Sales and Return fluctuate widely in the expected cyclical direction between "weakly positive" and "strongly negative," which is consistent with business cycle asymmetries: recessions are brisk and severe, expansions smoother (see McKay and Reis (2008)). The center-top panel shows, by contrast, that there are essentially no firms that report a negative effect of technology on capital expenditures, consistent with the notion that technology shocks are rarely negative, even at the idiosyncratic level. Furthermore, the panels for Finance and Macro confirm the "relatively unimportant"-diagnosis for these two investment determinants from above: almost always, even in severe recessions, more than half of the respondents attributed no role to them; even, by and large, for Finance in the Great Recession. Despite the importance of finance in the United States during that time, the Great Recession in Germany was not predominantly a financial crisis 15 Finally, the panel for Other shows that again more than half of the respondents attributed no role to this determinant most of the time, which we interpret as evidence that the IS is fairly exhaustive when it asks for investment determinants: the residual category is mostly unused, which means that no other major investment determinant appears to have been omitted from the questionnaire.

\subsection{Economic Content}

This subsection discusses the economic content of the aggregated investment determinant indices and and validates them against proxies for aggregate demand, technology, etc. The results in this subsection will be an important prerequisite for the narrative element in our identification strategy below. We start with Sales.

\footnotetext{
${ }^{15}$ We stress that this part of our results is unlikely to be generalizable to the US context, nor do we mean to say that finance or financial frictions are not important for investment decisions in general. Rather, the fact that most German firms rely on internal funds for investment financing (see Sections 2.4 for more on this issue) indicates the presence of major financial frictions in Germany. But these financial frictions appear to be a broader permanent institutional feature of the German economy that German firms just perceive as normal, rather than a contributor to the German business cycle.
} 
Sales Figure 4 compares Sales with various time series of general economic activity in the German manufacturing sector (revenues and industrial production), and, more specifically, a proxy for aggregate demand for this sector, that is, new orders. The upper-left panel of Figure 4 plots Sales and the cyclical component of the volume index of revenues in the German manufacturing sector, obtained from the Federal Statistical Office. The cyclical component is extracted by means of the HP-filter with a smoothing parameter of $\lambda=6.25$ for annual data, following Ravn and Uhlig (2002). The correlation between both time series is positive and high: 0.67 . The lower-left panel of Figure 4 displays real production in the German manufacturing sector, obtained from the Bundesbank, at business cycle frequencies $(\lambda=6.25)$. Again, the correlation with Sales is positive and high: 0.62 . Finally, in the upper-right panel of Figure 4, we plot the HP-filtered $(\lambda=6.25)$ index of new orders in the German manufacturing sector from the Bundesbank. The correlation with the investment determinant index Sales is 0.72. Especially this last piece of evidence is consistent with the view that the aggregate investment determinant index Sales captures the effect of aggregate demand on capital expenditures in the manufacturing sector.

Tech: In addition to capital expenditure data and investment determinants, the IS also asks, again in the fall questionnaire, about the fraction of total investment expenditures which in that year went into increases in capacity, restructuring, rationalization, maintenance, and other types of capital expenditures. First, we want to guard against the following possibility, which would be an alternative - to the neoclassical view - interpretation for Tech being consistently and on average above zero: whenever firms have to replace and maintain their capital stock due to continual wear and tear they answer that technological factors played an important role in their investment decisions. To this end, we use the fraction of total investment in a given year that was undertaken for maintenance reasons, pool all these observations across years and firms, sort them and compute for each tercile the investmentweighted average of Tech. Table 2 displays the results: if anything, for firm-year observations that have a high-maintenance content in their investment activity, Tech plays a relatively 
lower role than for those with a low-maintenance content. The differences in conditional means across terciles are statistically significant at the $1 \%$ level. We therefore find no evidence that Tech merely captures the maintenance and replacement of existing capital.

Next, we perform the flip side to the test in Table 2, namely, whether Tech is positively correlated with other forms of investment, especially those that are plausibly related to technological innovations: restructuring and rationalization investment. We thus sum the shares for restructuring and rationalization investment and repeat the analysis that led to Table 2. Table 3 shows the results: the investment-weighted average of Tech increases monotonically with the share of investment that went into restructuring and rationalization. The differences in conditional means across terciles are statistically significant at the $1 \%$ level. Therefore, for those firm-year observations that have a high innovation-content in their investment activity, Tech plays a relatively higher role, which makes it a plausible variable to identify technological innovations and their impact on investment decisions.

This interpretation is confirmed in our next test where we use another feature of the IS, which asked until 2001 (in the spring questionnaire) whether capital expenditures in the preceding year were targeted towards process innovations. The possible answers were "Yes" and "No". As before, we pool all firm-year observations, compute the investmentweighted averages of Tech conditional on these two answers, and compare them. Table 4 shows the results: Tech plays a relatively larger role for the investment activity of those firms that had capital expenditures targeted towards process innovations. Again, the difference in conditional means is statistically significant at the $1 \%$ level.

Finally, Eurostat provides a classification of three-digit manufacturing industries according to their technological intensity, defined as the ratio of industry R\&D spending to value added. Table 5 shows investment-weighted conditional means of the absolute value of Tech, conditional on three different R\&D intensity classes. 16 While the results are less clearly dis-

\footnotetext{
${ }^{16}$ For this exercise, we use the absolute value of Tech because the classification variable here is an importance variable at the industry-level, so we would expect both large positive and large negative values of Tech to be found in high technology industries with a higher frequency. In practice, since large negative values of Tech are rare, the results hold up had we used just plain Tech.
} 
positive than in the tests with firm-level characteristics $\$ 17$ - here we essentially assign to a firm the R\&D intensity of its industry, which creates statistical noise -, they nevertheless confirm the results using the IS firm-level data: the more technology-intensive a firm's industry is, the more important the role Tech plays in its investment activity on average.

In sum, the evidence in Tables 2 to 5 taken together, at least suggests that Tech captures indeed the effect of technological innovation factors on firms' capital expenditures.

Finance We next turn to Finance. From 1989 through 2001, the spring questionnaire of the IS featured a question about the share of capital expenditures funded by external finance in the preceding year. Finance should be more important as an investment determinant in firms that rely more on external finance. To investigate this hypothesis, we use the fraction of total investment in a given year that was funded by external finance, pool all these observations across years and firms, sort them and compute for each tercile the investment-weighted average of the absolute value of Finance. As Table 6 shows, two results from this exercise stand out. First, the cutoff value for the first tercile is exactly zero, and more than a third of all firm-year observations lie at this cutoff. That is, the majority of observations in the IS does not use any external funds for their capital expenditures. This finding is consistent with the fact that external finance in Germany plays a very limited role for investment financing. The Bundesbank (2012), for instance, reports that on average about two thirds of total corporate financing in Germany between 1991 and 2010 were raised through internal funds. Moreover, it corroborates the results in the previous section that Finance with its low mean is unlikely to be important for aggregate investment fluctuations in Germany.

Second, as Table 6 shows, the weighted mean of the absolute value of Finance indeed increases monotonically the more firms rely on external finance for their capital expenditures. For example, firms in the first tercile respond that financial factors had a 0.23 influence on capital expenditures (given the absolute value, on a scale between zero and two). On the

\footnotetext{
${ }^{17}$ The difference between firms in low and medium technology-intensive firms is statistically not significant, whereas the differences between any other pair of technological intensity bins are statistically significant at the $1 \%$ level.
} 
other hand, firms in the third tercile with more than $20 \%$ of investment financed through external funds state that financial factors had a 0.51 influence on their investment activity. The differences in conditional means between any two terciles are statistically significant at the $1 \%$ level.

In Figure 5 we compare, now in the time series dimension, Finance and two other covariate candidates. The top panel shows the yearly average of the monthly series of credit spreads for non-financial corporations from Gilchrist and Mojon (2016). Since this data is only available from 1999 onwards, we approximate, for the time before 1999, credit spreads as the difference between corporate bond yields, obtained from the Bundesbank, and 10-year German treasuries 18 Although corporate bonds are only a minor source of external finance in Germany, their yields are a good proxy for bank loans of different sizes and maturities, which are the major source of external finance for German firms 19 The correlation between Finance and credit spreads has the expected negative sign: -0.3 .

Similarly, in the lower panel of Figure 5, we compare Finance with a measure of idiosyncratic uncertainty in the West German manufacturing sector, the yearly average of the cross-sectional standard deviation of ex-post forecast errors from Bachmann et al. (2013). As Gilchrist et al. (2014) argue, uncertainty shocks can interact with financial frictions so as to cause an increase in the cost of capital followed by a decline in capital expenditures ${ }^{20}$ The correlation between the uncertainty measure and Finance, -0.3 , is consistent with this view:

\footnotetext{
${ }^{18}$ The maturity of the corporate bonds yield data does not match exactly with that of 10-year treasuries, as they include all "bonds with agreed maximum maturities of over four years if their mean residual maturities exceed three years", according to the Bundesbank. Nevertheless, the monthly and yearly correlation between our proxy and the credit spreads data by Gilchrist and Mojon(2016) is about 0.90 from 1999 onwards, when we can compare both time series. We thank Gilchrist and Mojon (2016) for providing us with their data.

${ }^{19}$ There does not appear to exist a good longitudinally consistent time series of bank loan interest rates for Germany. The interest rate statistics about euro-denominated loans to non-financial corporations which are resident in the euro area are available from the Bundesbank since 2003. These include loan rates for outstanding amounts and new business, up to 1 million Euro and over 1 million Euro, of German banks with maturity up to one year, between one and five years, or over five years. For the time before 2003, the European Central Bank provides data on national retail interest rates of German banks, broken down by short-term loans to enterprises and medium and long-term loans to enterprises. The correlation between corporate bond yields and the different lending rates is almost always above 0.80 for those periods where we have an overlap in the data.

${ }^{20}$ Other examples in the literature that study the link between investment activity and uncertainty through financial frictions are Christiano et al. (2014); Arellano et al. (2016); Dorofeenko et al. (2008).
} 
both panels together show that when idiosyncratic business uncertainty is up, for instance in all three identified recessions during our sample period, so are the credit spreads (and the average influence of Finance on investment tends to be negative then).

Taken together, the evidence presented in Table 6 and Figure 5 suggests that the effect of finance on capital expenditures is correctly captured by Finance, even though the cyclical fluctuations in Finance and at least credit spreads appear to be mild and thus make it unlikely that Finance is an independent driver of aggregate investment fluctuations.

Macro Figure 6 shows the time series of Macro, the investment determinant intended to capture macroeconomic policy, and potential fiscal policy covariate candidates. The relation between Macro and corporate tax policy is shown in the top panel. Since the firms in the IS are predominantly incorporated entities, which are under corporate tax law, we use the corporate tax rate. Its correlation with Macro is small: -0.10 . The lower panel plots Macro and a measure of real government purchases at business-cycle frequencies, that is, HP(6.25)-filtered. Government purchases are defined as the sum of intermediate inputs, wage costs, benefits in kind, and gross investment, obtained from German national accounting (Volkswirtschaftliche Gesamtrechnung, VGR) data on expenditures in the government sector. The correlation between the two series is also rather small: -0.18 .

Figure 7 shows the time series of Macro and two additional covariate candidates. The top panel displays the monetary policy rate. Until 1998 the discount rate set by the Bundesbank was the principal monetary policy instrument, followed by the main refinancing operations rate set by the European Central Bank. The correlation coefficient between both series, 0.16 , is small and has an unexpected sign 21 Increases in the monetary policy rate should depress economic activity through higher refinancing costs, and thus if Macro captured the monetary policy environment, we should expect a negative correlation with the monetary

\footnotetext{
${ }^{21}$ Perhaps the more precise statement is that there seems to be an unstable connection between the monetary policy rate and Macro: the post-reunification recession features the expected behavior, that is, monetary policy is tight and Macro has a negative influence on manufacturing investment, but afterwards Macro and the monetary policy rate mildly comove positively.
} 
policy rate. Also, the correlation between the monetary policy rate and the investment growth rate, $\Delta I_{t}^{F S O}$, is essentially zero: -0.01 . Taken together, this evidence suggests that, with the exception of the post-reunification recession, monetary policy is unlikely to be a major driver of aggregate investment fluctuations in Germany.

By contrast, the lower panel shows that Macro follows closely the cyclical component of real GDP, obtained from German VGR data and extracted by an HP-filter with smoothing parameter $\lambda=6.25$. The correlation between the two series is 0.46 . Taken together, the evidence in Figure 6 and Figure 7 suggests that the aggregate investment determinant index Macro does not capture fiscal or monetary policy per se, but rather appears to express the manufacturing firms' assessment of the general macroeconomic environment.

\subsection{Relation to Price-Setting Behavior}

This subsection, relying on the evidence from the previous subsection, focuses on Sales and Tech and uses a simple demand and supply framework to establish further the validity of both investment determinants by linking them, at the firm level, to price changes. In doing so, we hope to lend further credence to our survey-based approach. We show that what firms say in the survey corresponds to their actions. In addition, we lay the groundwork for the second part of the identification in our empirical strategy where we use correlation restrictions on manufacturing price inflation responses.

Relying on the usual predictions for prices following shifts in demand and supply, of which shifts in technology are a particular case, we investigate whether extensive-margin price changes are consistent with the reasons for investing given by the firms. More specifically, we test whether firms tend to raise prices when Sales stimulates investment, and conversely, whether they tend to lower prices when they say that Tech had a positive impact on their investment activity.

To do so, we match our sample with the ifo Business Cycle Survey, a different firmlevel survey at the ifo Institute. The ifo Business Cycle Survey is a monthly survey at the 
product level which, among other things, asks managers in manufacturing firms whether they increased or decreased the prices for their product or let them stay the same relative to the preceding month 22 We create dummy variables to flag price increases and price decreases. Using a correspondence table that links products in the Business Cycle Survey to firms in the IS, we first aggregate these variables at the firm level using the number of production workers for each product as weights, and then compute their yearly average. This procedure yields the frequency of monthly price increases/decreases at the firm level in any given year. We are able to match about $30 \%$ of firm-year observations in the IS.

We then estimate linear firm-level regressions of the frequency of price increases/decreases on Sales, Tech, and a constant ${ }^{23}$ Table 7 reports the results. Concentrating on the qualitative implications, Columns (1) and (5) show that firms raise prices more often and lower prices less frequently whenever they report that Sales has a positive influence as an investment determinant. The reverse holds true when Tech has a positive investment influence. Both findings are statistically significant. As Columns (2)-(4) and (6)-(8) of Table 7 show, these estimates are robust to including year fixed effects, year and industry fixed effects, and year and firm fixed effects. That is, the results are not driven by any particular years or industries and hold up to using only within-firm variation.

These findings provide evidence in support of the assumption that the firm-level survey responses contain information about the macroeconomic shocks that affect firms' investment decisions, and reinforce our interpretations of Sales and Tech in the previous subsection. More generally, they lend credence to the idea that subjective survey approaches can be informative because what survey respondents say in their answers corresponds, from an economic perspective, well to their actions.

\footnotetext{
${ }^{22}$ See Becker and Wohlrabe (2008) for a detailed description of the ifo Business Cyle Survey. It does not contain intensive-margin information on price changes.

${ }^{23}$ Here Sales and Tech refer to the firm-level survey responses from Section 2.1 before aggregation.
} 


\section{Empirical Setup}

The analysis in the previous section suggests a focus on the effects of aggregate demand and aggregate technology to understand aggregate investment fluctuations. However, as Table 1 showed, the associated narrative indicators, the investment determinants Sales and Tech, exhibit some correlation, and, as a result, they cannot yet be interpreted as independent shocks so that we cannot yet determine their contributions to aggregate investment fluctuations.24 To quantify the roles of aggregate demand and aggregate technology, we extract putatively exogenous and uncorrelated aggregate demand shocks and aggregate technology shocks, which requires imposing identifying assumptions. Given an estimate for these shocks, we then calculate their contribution to aggregate investment growth fluctuations.

\subsection{Identification}

Our identification strategy rests on two ideas, the groundwork for which we have laid in Sections 2.4 and 2.5. First, Sales is a narrative about demand conditions, and so we want aggregate demand shocks to be a key driver of this variable. By the same token, aggregate technology shocks should account for the bulk of variation in Tech, which measures the effects of technological factors on the investment activity of firms. This is the narrative part of our identification strategy.

Second, in many standard models aggregate demand shocks and aggregate technology shocks have different implications for prices. In particular, producer price inflation should be positively correlated with aggregate demand shocks while its correlation with technology shocks should be negative. This is the simple economic theory part of our identification strategy.25

\footnotetext{
${ }^{24}$ This is nothing unusual or uncommon when narrative evidence is brought to bear on macroeconomic questions. For instance, the narrative series for personal and corporate income tax changes by Mertens and Ravn (2013) are also correlated and are then orthogonalized to extract shocks to the corresponding taxes.

${ }^{25} \mathrm{In}$ earlier versions of the paper, we followed a recursive identification strategy assuming that only technology shocks affect Tech within a given year. By construction, this approach interprets all comovement between Sales and Tech as the result of technology shocks driving both variables. However, we found that technology shocks thus identified had a positive correlation with producer price inflation. We prefer iden-
} 
We implement these assumptions as follows. Let $\boldsymbol{u}_{\boldsymbol{t}}$ denote the vector stacking the reduced-form innovations to the investment determinant indices Sales, Tech, Finance, Return, Macro, and Other, in that order. We stress that these innovations have the interpretation of unexpected changes in the investment determinant indices, possibly after controlling for own lags and those of other variables. Our identifying assumptions then provide a mapping of structural shocks, e.g., aggregate demand shocks and aggregate technology shocks, into these surprise movements.

Consider the following characterization of $\boldsymbol{u}_{\boldsymbol{t}}$ in terms of a vector of orthogonal shocks $\boldsymbol{\eta}_{\boldsymbol{t}}$ :

$$
\boldsymbol{u}_{t}=\boldsymbol{P} \eta_{t}
$$

where $\boldsymbol{P}$ is the lower-diagonal Cholesky factor of the variance-covariance matrix of the reduced-form residuals, $\boldsymbol{\Sigma}_{\boldsymbol{u}}$. Of course, these orthogonal shocks are not necessarily the structural shocks we seek to isolate, for there is no reason that these shocks satisfy all identifying assumptions outlined above and described in more detail below. Using some orthogonal matrix $\boldsymbol{Q}$, the relationship between $\boldsymbol{u}_{t}$ and a candidate solution $\varepsilon_{t}^{*}$ for the structural shocks $\varepsilon_{t}$ can be written as

$$
u_{t}=P Q \varepsilon_{t}^{*}
$$

where $\boldsymbol{Q} \boldsymbol{Q}^{\boldsymbol{T}}=\boldsymbol{I}, \boldsymbol{\varepsilon}_{t}^{*}=\boldsymbol{Q}^{\boldsymbol{T}} \boldsymbol{\eta}_{t}$, and the product $\boldsymbol{P} \boldsymbol{Q}$ defines the mapping between $\varepsilon_{t}^{*}$ and $\boldsymbol{u}_{t}$. We stipulate that a candidate solution $\varepsilon_{t}^{*}$ is admissible for $\varepsilon_{t}$ if (i) the resulting aggregate demand shocks and aggregate technology shocks display a strong, positive, unconditional correlation with, respectively, Sales and Tech; (ii) the unconditional correlation between aggregate demand shocks and PPI inflation is positive; and (iii) the unconditional correlation between technology shocks and PPI inflation is negative. In the baseline specification we set the minimum correlation of structural shocks with our narrative investment determinants, because it relaxes the exclusion restrictions a researcher has to make under recursive identification. 
Sales and Tech, in (i) equal to 0.5; and the correlations with PPI inflation in (ii) and (iii) must be at least 0.005 in absolute value. We discard all candidate solutions that violate any of these correlation restrictions. Note that our empirical strategy is set-identified since in principle multiple candidate solutions may be admissible. Repeating this procedure for many different $\boldsymbol{Q}$ characterizes the set of all structural shocks that are consistent with the maintained correlation restrictions.

The matrix $\boldsymbol{Q}$ has the following block-diagonal form:

$$
Q=\left[\begin{array}{ll}
G & 0_{4} \\
0_{4} & I_{4}
\end{array}\right]
$$

where $\mathbf{0}_{\mathbf{4}}$ is a $4 \times 4$ matrix of zeros, $\boldsymbol{I}_{\mathbf{4}}$ is the $4 \times 4$ identity matrix, and $\boldsymbol{G}$ is a $2 \times 2$ rotation matrix that provides all possible combinations of aggregate demand shocks and aggregate technology shocks while preserving orthogonality.26 Moreover, because the matrix $\boldsymbol{Q}$ is block-diagonal, the product $\boldsymbol{P} \boldsymbol{Q}$ has a block-recursive form. In other words, multiplication of $\boldsymbol{P}$ by $\boldsymbol{Q}$ only affects the upper-left $2 \times 2$ block and leaves the remaining elements of $\boldsymbol{P}$ unchanged. Hence, the final four elements of $\varepsilon_{t}$ are orthogonal, Choleski-identified shocks to Finance, Return, Macro, and Other, after controlling for the effects of aggregate demand shocks and aggregate technology shocks as well as any variable ordered before in the Choleski-identification. This Choleski ordering essentially allows financial shocks to have their largest impact, once aggregate demand shocks and aggregate technology shocks are controlled for. Below we quantify the relevance of Finance, Return, Macro, and Other for aggregate investment fluctuations on which they indeed do not appear to have any relevant impact.

\footnotetext{
${ }^{26}$ We use Givens rotation matrices of the form $\boldsymbol{G}=\left[\begin{array}{cc}\cos \phi & -\sin \phi \\ \sin \phi & \cos \phi\end{array}\right]$, where $\phi \in[0,2 \pi]$ on a linearly-spaced grid with 1,000 points.
} 


\subsection{Baseline Specification}

Our benchmark estimates are based on a parsimonious specification excluding lags. In the robustness checks below we also estimate a dynamic specification that allows for lags.

Specifically, we start from a model in which the aggregate investment determinant indices fluctuate around their means:

$$
Y_{t}=\mu+u_{t}
$$

where $\boldsymbol{Y}_{t}=[$ Sales, Tech, Finance, Return, Macro, Other $], \boldsymbol{\mu}$ is a vector of constants, and $\boldsymbol{u}_{t}$ are the reduced-form innovations defined above. We estimate equation (6) by ordinary least squares (OLS). Given an estimate of $\boldsymbol{u}_{\boldsymbol{t}}$ and its variance-covariance matrix $\boldsymbol{\Sigma}_{\boldsymbol{u}}$, we follow the identification strategy outlined in the previous subsection to obtain the set of orthogonal shocks admissible under our correlation restrictions. For each of these shocks, we then estimate the following equation by ordinary least squares:

$$
\Delta I_{t}^{F S O}=c+\beta_{1}{\widehat{\operatorname{Sales}_{t}}}+\beta_{2} \widehat{\operatorname{Tech}}_{t}+\beta_{3} \overline{\text { Finance }}_{t}+\beta_{4} \widehat{\operatorname{Return}}_{t}+\beta_{5}{\widehat{\operatorname{Macro}_{t}}}+\beta_{6}{\widehat{\operatorname{Dther}_{t}}}_{t}+e_{t}
$$

where $\Delta I_{t}^{F S O}$ denotes aggregate investment growth, $c$ is a constant, and

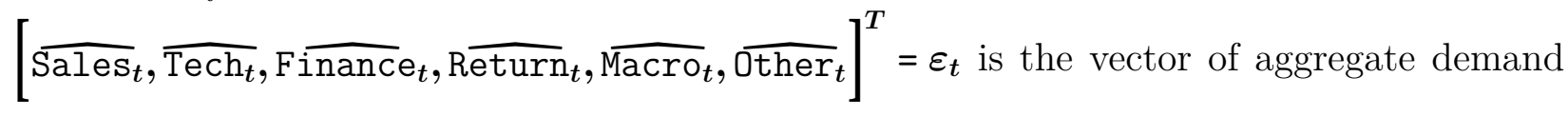
shocks, aggregate technology shocks, and other aggregate shocks for a given admissible solution, which we henceforth simply refer to as "orthogonal shocks". Given estimates of $\beta_{1}$ to $\beta_{6}$ in equation (7), we can compute the contribution of each orthogonal shock to the fluctuations in aggregate investment growth. To this end, we exploit the fact that the regressors are mutually orthogonal with unit variance, and therefore the total variance of $\Delta I_{t}^{F S O}$ can be written as:

$$
\operatorname{Var}\left(\Delta I_{t}^{F S O}\right)=\beta_{1}^{2}+\beta_{2}^{2}+\beta_{3}^{2}+\beta_{4}^{2}+\beta_{5}^{2}+\beta_{6}^{2}+\operatorname{Var}\left(e_{t}\right)
$$

We can then compute the contribution of the i-th orthogonal shock to the total variance of $\Delta I_{t}^{F S O}$ as $\frac{\beta_{i}^{2}}{\operatorname{Var}\left(\Delta I_{t}^{F S O}\right)}$. 


\section{Results}

\subsection{Aggregate Results}

\subsubsection{The Core Result}

Aggregate demand shocks cause the bulk of the fluctuations in aggregate manufacturing investment growth, as Table 8 shows. First, the $R^{2}$ for regression equation (7) is 0.81 , which means that more than eighty percent of the total variation in aggregate investment growth is explained jointly by the orthogonalized investment determinants from the IS. ${ }^{27}$ This result is important in its own right: the six orthogonal aggregate shocks identified from the survey explain a very sizable fraction of aggregate manufacturing investment growth variability documented in administrative statistics. Subjective survey information is thus highly informative of macroeconomic fluctuations, justifying our narrative approach also ex post.28

Second, using the variance decomposition in equation 8, the first column of panel A in Table 8 reports the range of the contributions over all admissible orthogonal shocks to the total variance of $\Delta I_{t}^{F S O}{ }^{29}$ The bulk of the fluctuations in aggregate investment growth can be attributed to $\overline{\text { Sales, }}$, that is, in our interpretation, to aggregate demand shocks, which account for between $65.92 \%$ and $74.81 \%$ of the total variance of $\Delta I_{t}^{F S O}$. Aggregate technology shocks at most account for $8.89 \%$. However, within the set of admissible shocks we also find estimates in which the contribution of aggregate technology shocks is essentially zero. The contributions of Finance, $\overline{\text { Return }}, \overline{\text { Macro }}$, and $\overline{\text { Other }}$ are small.

Panel B of Table 8, still first column, checks our identification assumptions and reports

\footnotetext{
${ }^{27}$ By construction, the total $R^{2}$ in equation (7) is the same for all admissible orthogonal shocks because admissible solutions for Sales and $\widehat{\text { Tech }}$ correspond to different linear combinations of Sales and Tech but leave the overall informational content of the explanatory variables unchanged.

${ }^{28}$ Only the coefficients on $\overline{\text { Sales }}$ and $\widehat{\mathrm{Tech}}, \beta_{1}$ and $\beta_{2}$, are ever statistically significant at the 5 percent level in the set of admissible orthogonalizations. None of the other orthogonal shocks are significant in any admissible rotation, justifying our focus on aggregate demand and aggregate technology shocks.

${ }^{29}$ Because of the block-recursive structure described in the previous section, the contributions to aggregate investment growth of Finance, $\overline{\text { Return }}, \overline{\text { Macro }}$, and $\overline{\text { Dther }}$ are point-identified.
} 
the range of the identifying correlations spanned by the admissible set. We start with the two narrative conditions. For example, the correlation coefficient between aggregate demand shocks and our survey-based indicator of aggregate demand conditions is almost always close to 1 , ranging from 0.95 to 1 , while the correlation coefficient between technology shocks and our survey-based indicator of technological factors ranges from 0.5 to 0.81 . Turning next to our simple economic theory identification conditions, the correlation coefficient between $\overline{\text { Sales }}$ and PPI inflation is positive, ranging between 0.47 and 0.52 . The correlation coefficient between admissible estimates of $\widehat{\mathrm{Tech}}$ and PPI inflation is negative and ranges from -0.01 to -0.22 .

It is useful to compare our set-identified results with two polar, point-identified estimates obtained through recursive identification. In the second column of Table 8, we report the Choleski-identified results with Sales ordered first, that is, from equation (3). In the third column of Table 8, we report the Choleski-identified results with Tech ordered first. The Choleski-identified results with Sales ordered first are useful because they provide us with a simple special, but representative case of the set-identified results, with which we can conduct a number of additional exercises below for semi-aggregate data, for which reporting a set of solutions would be intractable. Indeed, this identification scheme satisfies all four of our correlation restrictions, all of them in the interior 30 The resulting narrative correlation between $\widehat{\text { Sales }}$ and Sales is 0.75 , comfortably above the assumed threshold of 0.5. Corr ( $\overline{\text { Sales }}, \mathrm{PPI})$ is 0.51 , and Corr $(\widehat{\mathrm{Tech}}, \mathrm{PPI})-0.06$, that is both have the posited sign. Roughly 75 percent of aggregate investment growth fluctuations is explained by demand shocks in this specification, which is almost all of the total 81 percent that the orthogonalized investment determinants are able to explain.

The Choleski-identified results with Tech ordered first are interesting for two reasons: in this identification positive technology shocks are positively correlated with PPI inflation, which is why this recursive identification scheme is not contained in our set identification;

\footnotetext{
${ }^{30}$ Of course, in a Choleski-Sales-first identification one of the narrative correlations, that is, the correlation between $\overline{\text { Sales }}$ and Sales is 1 by construction.
} 
all other correlation criteria are satisfied. A researcher adhering to simple aggregate demand and aggregate supply reasoning would dismiss this identification scheme on theoretical grounds. However, panel A of Table 8, third column, makes also another point: even if a researcher does not adhere to such reasoning, only sticks to the narrative identification scheme, and wants to give aggregate technology shocks "the first shot" to explain aggregate investment growth fluctuations, aggregate demand shocks, now a residual after conditioning out aggregate technology shocks, would still explain the majority of these fluctuations: 44 percent, which is more than half of the total 81 percent that the orthogonalized investment determinants can explain 31

Next, we investigate the extent to which our results change if we loosen / strengthen the correlation thresholds for our two narrative identification assumptions to, respectively, $0.25 / 0.75$. The first and second columns of Table 9 show the results. Our main result is unchanged: aggregate demand shocks still explain the majority of the volatility of aggregate investment growth fluctuations. The possible contribution of aggregate technology shocks increases a bit with a looser threshold, it declines to nil with a higher threshold.

Finally, our core results is also robust to using real aggregate investment growth on the left-hand side of equation (7) 32 We use the deflator for gross fixed capital formation in the manufacturing sector, obtained from German national accounting data, to calculate growth rates of real investment, and then re-estimate the empirical model. The third column of Table 9 shows that the $R^{2}$ of equation $(7)$ even increases slightly to 0.84 . All other results remain, by and large, the same ${ }^{33}$

\footnotetext{
${ }^{31}$ Theories that do not rely on nominal rigidities to make aggregate demand shocks work, such as those in Angeletos et al. (2017) and Angeletos and La'O (2013), would not necessarily have the prediction that aggregate technology shocks are negatively correlated with PPI inflation. But, given this result, even they would be justified in highlighting the importance of aggregate demand shocks. We thank George-Marios Angeletos for this point.

${ }^{32}$ Given that the survey asks about nominal investment expenditures at the firm-level, we used, as a first pass, nominal investment expenditures also for the aggregate. It is reassuring, however, that our results are essentially unchanged when using real aggregate investment growth. If anything, the IS orthogonalized investment determinants explain a higher fraction of the variance of real aggregate investment growth.

${ }^{33}$ In addition to their instantaneous effect on investment, technology shocks might have dynamic effects on capital expenditures. In the presence of adjustment costs, lagged values of technology might affect aggregate capital expenditures in the current period. Similarly, with news about its future level, technology one
} 


\subsubsection{A Counterfactual Simulation}

A slightly different perspective on our core result can be obtained from computing a counterfactual aggregate investment growth rate series sans aggregate demand shocks: this counterfactual series loses its essential cyclical properties. To be specific, we subtract, for each of the admissible orthogonalizations, the contributions of aggregate demand shocks, $\beta_{1} \widehat{\operatorname{Sales}_{t}}$, from the fitted investment growth rate series estimated in equation (7), and depict these counterfactual series as pointwise minima and maxima along with the fitted series and the data $\Delta I_{t}^{F S O}$ in Figure 8 .

Figure 8 shows that almost none of the officially declared recession years would have experienced negative investment growth without the aggregate demand shocks, in contrast to the data. The reunification boom would not exist, neither would the prolonged slump in the early 2000s even beyond the official recession. There would have been no investment boom nor a rebound around the Great Recession. In other words, without aggregate demand shocks, the counterfactual aggregate investment growth rate series does not resemble the narrative history of the German post-reunification business cycle. Aggregate demand shocks are thus essential for our understanding of this business cycle.

\subsubsection{Potential Misclassification of Shocks: Inter-Industry Effects}

Thus far, we have implicitly assumed that the shocks we identify are manufacturing-aggregate shocks, and that industry-specific shocks "average out". However, because of input-output linkages between firms of different industries, survey respondents from different industries may have different perceptions of such industry-specific shocks. Industry-specific shocks of one kind may spill over and lead to aggregate fluctuations perceived as another kind. To be concrete, suppose there is a technology shock that is specific to industry $i$, the firms year ahead might have an impact on investment in the current period. However, when we re-estimate the regression equation (7) with the Choleski-Sales-first-identified shocks and include a lead and a lag of the aggregate technology shock, these coefficients are insignificant, nor do they increase the $R^{2}$ of the regression meaningfully. We conclude that we do not miss contributions of technology shocks from the mentioned dynamic effects. For a more comprehensive treatment of dynamics, see Section 4.1.6. 
of which might now want to invest and produce more and thus need more inputs from other, upstream industries $j$, so that these industries would experience an increase in their demand-related investment determinant: in particular, if industry $i$ had a small investment share in aggregate manufacturing investment but bought large amounts of inputs from other manufacturing industries, we might erroneously classify an industry-specific technology shock as an aggregate demand shock. Because sector-specific technology shocks induce additional demand for intermediate goods in this case, we label this channel the upstream channel.

There might also be another effect, a downstream channel: suppose firms from industry $i$ make an invention that is sold to other, downstream industries $j$, which would show up for industry $i$ as a demand-related investment determinant, while it would be a technologyrelated one for industries $j$. In particular, if industry $i$ had a large investment share in aggregate manufacturing investment, we might erroneously classify an industry-specific (and investment-specific) technology shock as an aggregate demand shock. ${ }^{34}$

Using input-output tables from the Federal Statistical Office, we can gauge whether these inter-industry effects are likely to be quantitatively important 35 To evaluate the upstream channel, we compute the shares of goods which 2-digit manufacturing industry $i$ buys from every other 2-digit manufacturing industry $j, \lambda_{i}^{j}$, normalize them to sum to unity, and define an upstream index for industry $i, \mathrm{USI}_{t}^{i}$, as the input-share-weighted demand shocks of every other industry $j$ :

$$
\mathrm{USI}_{t}^{i}=\sum_{j \neq i} \lambda_{i}^{j} \widehat{\operatorname{Sales}}_{j t}
$$

where $\widehat{\operatorname{Sales}_{j t}}$, for reasons of simplicity and pragmatism, are the industry-specific demand shocks for industry $j$, using the Choleski-Sales-first identification scheme on data from each 2-digit manufacturing industry individually.

\footnotetext{
${ }^{34}$ Such spill over and thus potential misclassification effects could also come from outside of manufacturing. Our data do not allow us to deal with this issue, so that our shocks are always identified as "as perceived by the manufacturing sector."

${ }^{35}$ We have these input-output linkage data for the years 1995, 2000, and 2005. Since the variation of these shares over time is small, we take the average intermediate output shares over the three years. We drop 'Mining' for this exercise because the number of observations per cross-section in the IS is small for this sector. See Footnote 6
} 
Similarly, to evaluate the downstream channel, we define the following downstream index for industry $i, \operatorname{DSI}_{t}^{i}$ :

$$
\operatorname{DSI}_{t}^{i}=\sum_{j \neq i} \mu_{i}^{j} \widehat{\operatorname{Tech}_{j t}}
$$

where $\mu_{i}^{j}$ are the shares of goods which 2-digit manufacturing industry $i$ sells to every other 2-digit manufacturing industry $j$, normalized to sum to unity, and $\widehat{\operatorname{Tech}_{j t}}$ are the technology shocks for industry $j$, again obtained by a Choleski-Sales-first identification scheme applied to 2-digit manufacturing industry data.

Table 10 reports the coefficients of regressions of, respectively, $\mathrm{USI}_{t}^{i}$ on $\overline{\operatorname{Tech}_{i t}}$ (in panel $\mathrm{A}$ ), and $\operatorname{DSI}_{t}^{i}$ on $\overline{\operatorname{Sales}_{i t}}$ (in panel B), their standard errors, and the corresponding $R^{2}$. If shock misclassification was a major issue, we would expect at least some of these regressions to have significant coefficients and large $R^{2}$, which is, however, not the case.

The estimated coefficients are generally insignificant and the $R^{2}$ of these regressions are low: for the upstream channel, the slope coefficient is only significant in the 'Food, Tobacco'industry, and the $R^{2}$ for that industry is about 12 percent. For the downstream channel, it is again only in the 'Food, Tobacco'-industry where the slope estimate is significant and the $R^{2}$ is 13 percent. ${ }^{36}$ In particular, we find no evidence of inter-industry effects for the largest manufacturing subsector 'Machines, Cars, and Other Heavy Manufacturing', which has an investment share of about 55 percent. 37

In sum, there is little evidence that original technology shocks in one small industry with a high manufacturing input share get misclassified as (essentially aggregate) demand shocks in the rest of the manufacturing industries; there is also little evidence that original technology shocks in one large industry get misclassified as aggregate demand shocks.

\footnotetext{
${ }^{36}$ For the upstream channel to be important through 'Food, Tobacco', this industry would have to have an important contribution of technology shocks to its investment fluctuations, which is not the case: approximately 5 percent. To be important through the downstream channel, this industry would have to be large, but its fraction in manufacturing investment is less than 7 percent (see Table 10p).

${ }^{37}$ The lack of a downstream channel for this particular machine-producing industry also suggests that, more specifically, investment-specific technology shocks may not play an important role for investment fluctuations in Germany.
} 


\subsubsection{Suggestive Evidence on the Nature of the Aggregate Demand Shocks}

Since aggregate demand shocks seem to play a substantial role for fluctuations in aggregate investment growth, we next examine somewhat more closely where they might come from: do they capture confidence/sentiment, or rather macroeconomic policy? Figure 9 plots, in three different panels, the pointwise minima and maxima of $\overline{\text { Sales }}$ over all admissible orthogonalizations, together with proxy series for confidence: the GfK Consumer Confidence Index. ${ }^{38}$ the aggregate business situation index for the West German manufacturing sector from the ifo Business Cycle Survey, which captures the current business situation of respondents, and the aggregate business expectations index for the West German manufacturing sector, which summarizes forward-looking questions in the ifo Business Cycle Survey. We use the yearly averages of the monthly confidence series. The set of pairwise correlations between $\overline{\text { Sales }}$ in all admissible orthogonalizations and each of the sentiment indices reveals a fairly strong association between our identified aggregate demand shocks and these proxies for confidence: the median $\sqrt{39}$ correlation between consumer confidence and $\overline{\text { Sales }}$ is $0.56([0.48,0.60]$ being the range), between business situation and $\overline{\text { Sales }}$ it is 0.80 ([0.72, 0.84] being the range), and between business expectations and $\overline{\text { Sales }}$ it is $0.42([0.32,0.49]$ being the range). That is, especially the index capturing current business situations is highly correlated with our identified aggregate demand shock series, consistent with the work by Angeletos et al. (2017), who also find that shocks to sentiment can account for a sizable fraction of aggregate investment and output fluctuations ${ }^{40}$

Macro policy shocks are another conceivable driver of $\overline{\text { Sales. }}$. Figure 10 therefore plots $\overline{\text { Sales}}$, again as the pointwise minima and maxima of Sales over all admissible orthogonalizations, together with those policy variables for fiscal and monetary policy with which we compared the Macro index (see the discussion in Section 2.4 above, and, in particular, Figures 6 and 7). If our aggregate demand shocks were mostly driven by policy shocks, we

\footnotetext{
${ }^{38}$ GfK: Gesellschaft für Konsumforschung (Society for Consumption Research).

${ }^{39}$ Results for the average correlation are nearly identical.

${ }^{40}$ We find no evidence of news about future technology à la Barsky and Sims (2012) driving these confidence variables.
} 
would expect that they are strongly negatively (positively) correlated with the corporate tax rate or the monetary policy rate (government purchases). However, Figure 10 shows that two of the three pairwise correlation coefficients between $\overline{\text { Sales }}$ and the policy variables have the "wrong" sign. The correlation between the corporate tax rate and demand shocks is mildly positive, ${ }^{41}$ while the correlation with government purchases is mildly negative, 42 pointing to mildly countercyclical expenditure policy rather than fiscal policy being a driver of the business cycle. Only the correlation with the monetary policy rate is weakly negative, as expected 43 This sign, however, is mostly driven by one particular episode, the post-reunification recession (and its immediate subsequent recovery) caused by a large contractionary monetary policy shock, which is picked up by a large negative effect of $\overline{\text { Sales }}$, which, in turn, lets aggregate investment and sentiment collapse. ${ }^{44}$ Overall, however, while simple correlations are not dispositive, and the absence of evidence - such as is the case for the most part with the correlations between $\overline{\text { Sales }}$ and macro policy variables - is not as strong as direct evidence, the available information on $\overline{\text { Sales }}$ and a number of confidence indicators is at least consistent with $\overline{\text { Sales }}$, and thus, by extension, fluctuations in aggregate investment, being driven mostly by sentiment movements.

\subsubsection{Effects on Industrial Production}

In this section, we investigate whether our set-identified aggregate shocks, estimated from investment-related data, can also explain output (growth) fluctuations. To this end, we regress industrial production growth in the manufacturing sector on the set of admissible orthogonal shocks identified in Section 3.2, and compute their contributions to the overall variance of industrial production growth, as described for investment growth in equation (8).

Table 11 shows the results of this analysis. The $R^{2}$ of the estimating regression is approx-

\footnotetext{
${ }^{41}$ The median correlation is 0.32 ranging between 0.28 and 0.34 .

${ }^{42}$ The median correlation is -0.16 ranging between -0.16 and -0.15 .

${ }^{43}$ The median correlation is -0.22 ranging between -0.24 and -0.19 .

${ }^{44}$ The median correlation is 0.04 ranging between 0.02 and 0.06 , when we compute the correlations between the monetary policy rate and the admissible $\overline{\text { Sales }}$ on the sample starting in 1998.
} 
imately 0.73 , which means that also a sizable fraction of output growth fluctuations can be explained by our aggregate shocks that were identified from investment reasons. This finding lends additional external validity to our procedure. And again, the bulk of the fluctuations in industrial production growth can be attributed to aggregate demand shocks, with a contribution range between 50 percent and 63 percent to the total variance, while the contribution of technology shocks to output growth fluctuations is small, ranging from 0 to 13 percent.

\subsubsection{An Alternative Empirical Strategy: a VAR}

In the baseline specification, equations (6) and (7), we omitted, in the interest of parsimony, both lags of the left-hand side variable, $\Delta I_{t}^{F S O}$, and lags of the investment determinants. The obvious alternative would be to estimate a vector autoregression (VAR) to obtain an estimate of the reduced-form residuals $\boldsymbol{u}_{t}$ and then apply the same identification strategy as in Section 3.1. For example, Romer and Romer (2004), also include narratively identified shocks in VARs. VARs are designed to model dynamic interactions between variables and serial correlation in them. One of the disadvantages of VARs, however, is their highly parameterized nature: if we wanted to estimate a first-order VAR that included aggregate investment growth and all six investment determinants, we would have to estimate 84 parameters.

However, with the results from the previous subsections in mind that aggregate investment growth is mostly determined by two factors, Tech, Sales, we can employ a lowerparameterized VAR in these two determinants plus $\Delta I_{t}^{F S O}$ and PPI inflation to check the robustness of our baseline results 45

Formally, let $\boldsymbol{F}_{\boldsymbol{t}}=\left(\operatorname{Sales}_{t}, \mathrm{Tech}_{t}\right)^{T}$. Also, let the joint dynamics of $\boldsymbol{F}_{\boldsymbol{t}}, \Delta I_{t}^{F S O}$, and PPI inflation be governed by the following $\operatorname{VAR}(1)$ :

\footnotetext{
${ }^{45}$ We also note that a VAR is an alternative to address the concern we have discussed in footnote 33 in the context of technology shocks, namely, that lagged shocks may influence current investment growth because of, e.g., capital or investment adjustment costs.
} 


$$
\left[\begin{array}{c}
\boldsymbol{F}_{\boldsymbol{t}} \\
\Delta I_{t}^{F S O} \\
P P I_{t}
\end{array}\right]=\boldsymbol{\nu}+\boldsymbol{\Phi}\left[\begin{array}{c}
\boldsymbol{F}_{\boldsymbol{t}-\mathbf{1}} \\
\Delta I_{t-1} \\
P P I_{t-1}
\end{array}\right]+\boldsymbol{u}_{\boldsymbol{t}}
$$

where $P P I_{t}$ denotes PPI inflation, $\nu$ is a $4 \times 1$ vector of constants and $\Phi$ is a coefficient matrix. Given an estimate of the reduced-form innovations and their variance-covariance matrix, we follow the same steps outlined in Section 3.1 to identify orthogonal shocks. This procedure effectively extends our baseline specification to a dynamic context by controlling for the past behavior of all variables in the VAR.

Figure 11 plots the impulse response functions of each variable in the system in response to aggregate demand shocks (left panels) and aggregate technology shocks (right panels), with a size of one standard deviation for each. The solid blue lines show the impulse responses based on the pointwise median across all admissible solutions, while the dashed black lines show the corresponding pointwise minima and maxima. The third row of Figure 11 depicts the IRFs of interest: a negative but mild and delayed one-off effect of technology shocks on aggregate investment growth, and a strongly positive and persistent effect of aggregate demand shocks on aggregate investment growth.

Table 12, in panel A, displays the (range of the) forecast error variance contributions at the five-year horizon 46 for each variable of interest, $\Delta I_{t}^{F S O}$ and $P P I_{t}$, and for the aggregate demand and aggregate technology shocks. We do so for the set-identified correlation restrictions approach as well as for two polar Cholesky identification schemes: Sales first and Tech first. The first result from this table is that, just as in the baseline empirical approach without lags, our identified aggregate demand and aggregate technology shocks derived from survey-based narratives explain the largest share of aggregate investment growth fluctuations. Put differently, the residual third and fourth shocks on $\Delta I_{t}^{F S O}$ and $P P I_{t}$ are of minor

\footnotetext{
${ }^{46}$ Given the yearly frequency and the small serial correlation present in the impulse response functions, the five-year horizon forecast error variance decomposition corresponds essentially to the long-run, i.e., the unconditional variance of each variable.
} 
importance. And even for PPI fluctuations, both interpretable shocks together still explain approximately a third of the total variance.

Secondly, independently of the identification scheme, our other result from the baseline empirical approach, that is, that aggregate demand shocks explain the majority of aggregate investment growth fluctuations is also confirmed here 47

To sum up, our results are by and large robust to modelling dynamics explicitly. Aggregate demand shocks still account for much more than half of aggregate investment fluctuations, while aggregate technology shocks gain somewhat in importance, but still explain maximally about 22 percent of the aggregate investment growth variance 48

\subsection{Semi-Aggregate Results}

In this subsection we show that our core result that demand shocks explain the bulk of aggregate investment fluctuations is not a mere composition effect and is largely replicated in most manufacturing industries and at a regionally more disaggregate level.

Thus far, and with one exception in Section 4.1.3, our analysis has focused on the WestGerman manufacturing aggregate and common shocks that affect all manufacturing industries. Next, we use semi-aggregate specifications at the two-digit industry level, and at the German state, the Laender level, to investigate whether there are quantitatively important heterogeneities in the driving forces of investment fluctuations. Using the weights defined in Section 2.2, we first compute investment determinant indices by two-digit industry and by

\footnotetext{
${ }^{47}$ We note that unlike in the baseline empirical approach, neither Cholesky identification is inside the set of admissible orthogonalizations, including the Sales-first one, as panel B of Table 12 shows. Nevertheless, the Choleski-Sales-first identification scheme "misses just barely", with the resulting identified aggregate technology shock exhibiting the very small positive correlation of 0.04 with PPI. By contrast, the CholeskiTech-first identification scheme misses by more, with the resulting identified aggregate technology shock exhibiting a PPI correlation of 0.23 . In this sense, we corroborate the practice in some places in the paper to use, for practicality reasons, the Choleski-Sales-first identification scheme as a stand-in for our baseline correlation-based identification scheme.

${ }^{48}$ Indeed, the pairwise correlations between all the admissible orthogonal shocks from the VAR and all the admissible orthogonal shocks from the baseline specification ranges from 0.73 to 0.81 for aggregate demand shocks ( 0.79 being the median), and from 0.82 and 0.87 for aggregate technology shocks ( 0.85 being the median). These correlation numbers also suggests that both procedures uncover essentially the same economic shocks.
} 
Land. We have eight industries: ${ }^{49}$ Chemical Industry, Oil; Plastics, Rubber; Glass, Ceramics; Metals; Machinery; Wood, Paper, Printing; Textiles, Leather; Food, Tobacco. For the Laender split we use eight out of the eleven West German Laender: Baden-Württemberg, Bavaria, Hamburg, Hesse, Lower Saxony, North Rhine-Westphalia, Rhineland-Palatinate, and Schleswig-Holstein 50

Throughout this subsection, we use the Choleski-Sales-first identification scheme separately for each industry/Land to quantify the contribution of each orthogonal shock to the corresponding investment growth rates. The left-hand-side official investment growth rates by industry are for West Germany until 1991, but from 1992 they are for Germany as a whole (a finer split is not available at the 2-digit level); the Laender investment growth rates are only available since 1992 and only as total industrial (not just manufacturing) investment growth rates, which means we have a slightly shorter sample period in the Laender exercise.

Figure 12 displays box-plots of the estimates for the contributions of orthogonal shocks to the total variance of investment growth at the two-digit industry level. The rightmost box-plot shows the $R^{2}$ of the industry-level regressions. While the explanatory power of our survey-based investment determinant indices slightly decreases at the semi-aggregate level, the $R^{2}$ still remains above two third in most of the industries. The median of the $R^{2}$ across all industries is 0.73 .

The first box-plot of Figure 12 displays the contribution of $\overline{\operatorname{Sales}}_{i}$ to variations in the two-digit industry-level investment growth rates. The finding that $\overline{\text { Sales }}$ explains the bulk of short-run fluctuations in investment largely carries over to this level of aggregation. The twodigit industry-level median estimate is approximately $65.2 \%$, and the range goes from $40 \%$ in 'Coal, Chemicals, and Petroleum' to $76 \%$ in 'Rubber, Plastics'. The variance contributions of the other orthogonal shocks are small. Altogether, the result that most two-digit industries

\footnotetext{
${ }^{49}$ The IS records the four-digit WZ03 and WZ08 industrial classification codes from 2003 and 2008, respectively, used in the German national accounting system. From these we map the firm-level observations into two-digit industries. We drop data for the 'Mining' sector for this exercise because the number of observations in the cross-section of this industry is small in the IS. See Footnote6

${ }^{50}$ We drop data from Bremen, Saarland and West Berlin for this exercise because cross-sections from these Laender in the IS are small, just as the Laender themselves.
} 
behave like the aggregate combined with the lack of evidence for strong inter-industry shock effects (see Section 4.1.3) suggests that our aggregate baseline specification is a good empirical approach and that aggregate shocks account for the bulk of aggregate investment fluctuations.

The Laender results are shown in Figure 13 . The median overall $R^{2}$ across all Laender is 0.54 . The contributions of $\overline{\operatorname{Sales}}_{i}$ to regional investment growth is qualitatively and, to a large extent, quantitatively similar to the results for the aggregate and the two-digit industry-level.

In sum, the semi-aggregate evidence presented in this subsection lends support to the finding from aggregate data that the majority of investment fluctuations is explained by demand shocks, while other shocks seem to play only a minor role, if any, in the German investment cycle. Tables 13 summarizes these findings by displaying the investment-weighted variance contributions across, respectively, all eight manufacturing 2-digit industries and eight West German Laender. Our disaggregate results, which, to a large extent, replicate the aggregate findings on many time series, also alleviate somewhat the concern that these aggregate results might be spurious because they are estimated from a relatively short time series.

\section{Conclusion}

This paper proposes and uses a novel empirical strategy to address a seminal question in macroeconomics: the sources of aggregate fluctuations, here investment fluctuations. We use survey data from the ifo Investment Survey about subjective investment determinants combined with a narrative approach to uncover what drives the dynamics of investment in the West German manufacturing sector. Consistent with neoclassical views of the economy, we find that, on average, technology is the most important investment determinant. Regular year-to-year fluctuations in both investment and output, however, are best explained by aggregate demand shocks that appear to be related to business and consumer sentiment. 
More generally, this paper also makes a methodological contribution. We show that survey-based subjective reasons for a particular economic action taken can be high in economic content and measure what they are designed to measure. Based on these insights, we then show that such data can be leveraged to explain a significant portion of aggregate fluctuations. Our results thus call for the inclusion of subjective reason data in the economics toolbox and for a heightened effort to collect such data. 


\section{References}

Alexopoulos, M. (2011): "Read All about It!! What Happens Following a Technology Shock?" American Economic Review, 101, 1144-1179.

Angeletos, G.-M., F. Collard, And H. Dellas (2017): "Quantifying Confidence," Mimeo, Massachusetts Institute of Technology.

Angeletos, G.-M. And J. LA'O (2013): "Sentiments," Econometrica, 81, 739-779.

Arellano, C., Y. Bai, And P. J. Kehoe (2016): "Financial Frictions and Fluctuations in Volatility," NBER Working Paper 22990.

Bachmann, R., T. O. Berg, and E. R. Sims (2015): "Inflation Expectations and Readiness to Spend: Cross-Sectional Evidence," American Economic Journal: Economic Policy, $7,1-35$.

Bachmann, R. And S. Elstner (2015): "Firm Optimism and Firm Pessimism," European Economic Review, 79, 297-325.

Bachmann, R., S. Elstner, And A. Hristov (2017): "Surprise, Surprise - Measuring Firm-level Investment Innovations," Journal of Economic Dynamics and Control, 83, 107148.

Bachmann, R., S. Elstner, And E. Sims (2013): "Uncertainty and Economic Activity: Evidence from Business Survey Data," American Economic Journal: Macroeconomics, 5, $217-249$.

Barsky, R. And E. Sims (2012): "Information, Animal Spirits, and the Meaning of Innovations in Consumer Confidence," American Economic Review, 102, 1343-1377.

Basu, S., J. G. Fernald, And M. S. Kimball (2006): "Are Technology Improvements Contractionary?" American Economic Review, 96, 1418-1448. 
Becker, S. O. And K. Wohlrabe (2008): "Micro Data at the Ifo Institute for Economic Research - The "Ifo Business Survey", Usage and Access," Schmollers Jahrbuch, 128, 307-319.

Bewley, T. (1999): Why Wages Don't Fall During a Recession, Harvard University Press.

Blanchard, O. and R. Perotti (2002): "An Empirical Characterization of the Dynamic Effects of Changes in Government Spending and Taxes on Output," The Quarterly Journal of Economics, 117, 1329-1368.

Blanchard, O. And D. Quah (1989): "The Dynamic Effects of Aggregate Demand and Supply Disturbances," American Economic Review, 79, 655-673.

Bocola, L., M. Hagedorn, And I. Manovskit (2014): "Identifying Neutral Technology Shocks," Mimeo, University of Pennsylvania.

Bundesbank (2012): "Monthly Report January 2012," Deutsche Bundesbank.

Carroll, C. and W. Dunn (1997): "Unemployment Expectations, Jumping (S,s) Triggers, and Household Balance Sheets," NBER Macroeconomics Annual, 12, 165-229.

Chari, V. V., P. J. Kehoe, and E. R. McGrattan (2007): "Business Cycle Accounting," Econometrica, 75, 781-836.

Christiano, L., M. Eichenbaum, and C. Evans (1996): "The Effects of Monetary Policy Shocks: Evidence from the Flow of Funds," The Review of Economics and Statistics, $78,16-34$.

Christiano, L. J., R. Motto, and M. Rostagno (2014): "Risk Shocks," American Economic Review, 104, 27-65.

Dorofeenko, V., G. S. Lee, And K. D. Salyer (2008): "Time-Varying Uncertainty And The Credit Channel," Bulletin of Economic Research, 60, 375-403. 
Gennaioli, N., Y. Ma, And A. Shleifer (2015): "Expectations and Investment," NBER Macroeconomics Annual, 30, 379-431.

Gilchrist, S. And B. Mojon (2016): "Credit Risk in the Euro Area," The Economic Journal, forthcoming.

Gilchrist, S., J. Sim, And E. Zakrajsek (2014): "Uncertainty, Financial Frictions, and Investment Dynamics," Mimeo, Boston University.

Guiso, L. And G. PARIGi (1999): "Investment and Demand Uncertainty," The Quarterly Journal of Economics, 114, 185-227.

Kocherlakota, N. (2009): "Modern Macroeconomic Models as Tools for Economic Policy," Annual Report Essay, Federal Reserve Bank of Minneapolis.

Ludvigson, S. C., S. MA, And S. NG (2017a): "Shock Restricted Structural VectorAutoregressions," NBER Working Paper 23225.

(2017b): "Uncertainty and Business Cycles: Exogenous Impulse or Endogenous Response?" Mimeo, New York University.

Malmendier, U. And S. NAGEL (2016): "Learning from Inflation Experiences," Quarterly Journal of Economics, 131, 53-87.

McKay, A. And R. ReIs (2008): "The Brevity and Violence of Contractions and Expansions," Journal of Monetary Economics, 55, 738-751.

Mertens, K. and M. O. Ravn (2013): "The Dynamic Effects of Personal and Corporate Income Tax Changes in the United States," The American Economic Review, 103, 12121247.

Nerlove, M. (1983): "Expectations, Plans, and Realizations in Theory and Practice," Econometrica, 51, 1251-1279. 
Ramey, V. (2016): "Macroeconomic Shocks and Their Propagation," in Handbook of Macroeconomics, ed. by J. Taylor and H. Uhlig, Elsevier, vol. 2A, chap. 2, 71-162.

Ravn, M. O. And H. Uhlig (2002): "On Adjusting the Hodrick-Prescott Filter for the Frequency of Observations," The Review of Economics and Statistics, 84, 371-376.

Romer, C. D. And D. H. Romer (2004): "A New Measure of Monetary Shocks: Derivation and Implications," The American Economic Review, 94, pp. 1055-1084.

(2010): "The Macroeconomic Effects of Tax Changes: Estimates Based on a New Measure of Fiscal Shocks," The American Economic Review, 100, pp. 763-801.

SACHVERSTÄNDigenRAT (2017): "Für eine zukunftsorientierte Wirtschaftspolitik Jahresgutachten 2017/18," Tech. rep.

Smets, F. And R. Wouters (2007): "Shocks and Frictions in US Business Cycles: A Bayesian DSGE Approach," American Economic Review, 97, 586-606.

Souleles, N. S. (2004): "Expectations, Heterogeneous Forecast Errors, and Consumption: Micro Evidence from the Michigan Consumer Sentiment Surveys," Journal of Money, Credit and Banking, 28, 39-72.

Stock, J. And M. Watson (2012): "Disentangling the Channels of the 2007-09 Recession," Brookings Papers of Economic Activity, 81-156, Spring.

(2016): "Dynamic Factor Models, Factor-Augmented Vector Autoregressions, and Structural Vector Autoregressions in Macroeconomics," in Handbook of Macroeconomics, ed. by J. Taylor and H. Uhlig, Elsevier, vol. 2A, chap. 8, 415-525.

Uhlig, H. (2004): "Do Technology Shocks Lead to a Fall in Total Hours Worked?" Journal of the European Economic Association, 2, 361-371. 
Figure 1 - Comparison of Aggregate Investment Growth from ifo and the Federal Statistical Office $(\rho=0.89)$

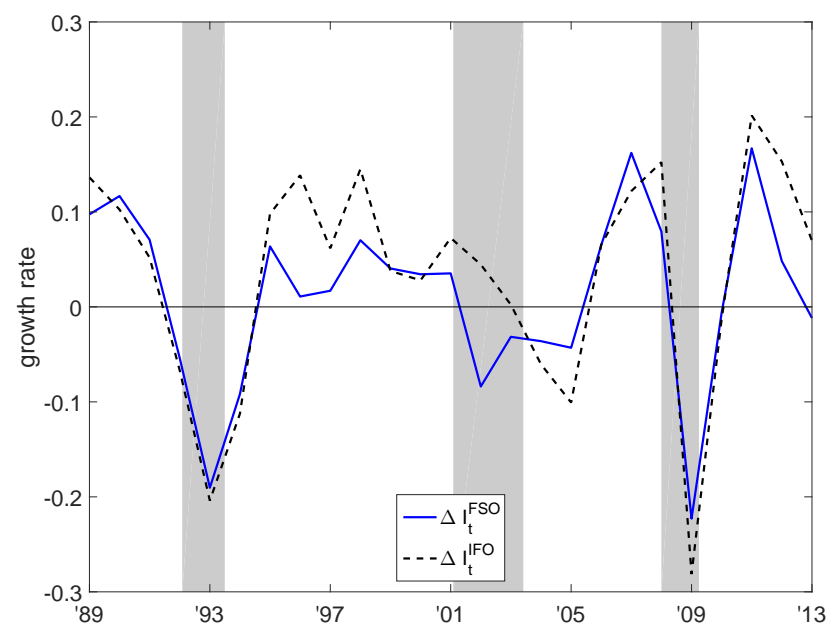

Notes: This figure plots two time series of the aggregate investment growth rate in the West German manufacturing and mining sector. $\Delta I_{t}^{F S O}$ is administrative data provided by the Federal Statistical Office. Up to and including 2011, it comprises the West German manufacturing and mining sector. From 2012 onwards, $\Delta I_{t}^{F S O}$ is available only for unified Germany. $\quad \Delta I_{t}^{I F O}$ is the growth rate implied by the ifo Investment Survey, obtained from aggregating the firm-level responses to Q1 with weights as described in the text. The correlation coefficient between $\Delta I_{t}^{F S O}$ and $\Delta I_{t}^{I F O}, \rho$, is 0.89 . The gray-shaded regions show recessions as dated by the Sachverständigenrat (see Sachverständigenrat, 2017, p. 134): 1992:M02 - 1993:M07, 2001:M02 - 2003:M06, 2008:M01 - 2009:M04.

Figure 2 - Aggregate Investment Determinant Indices
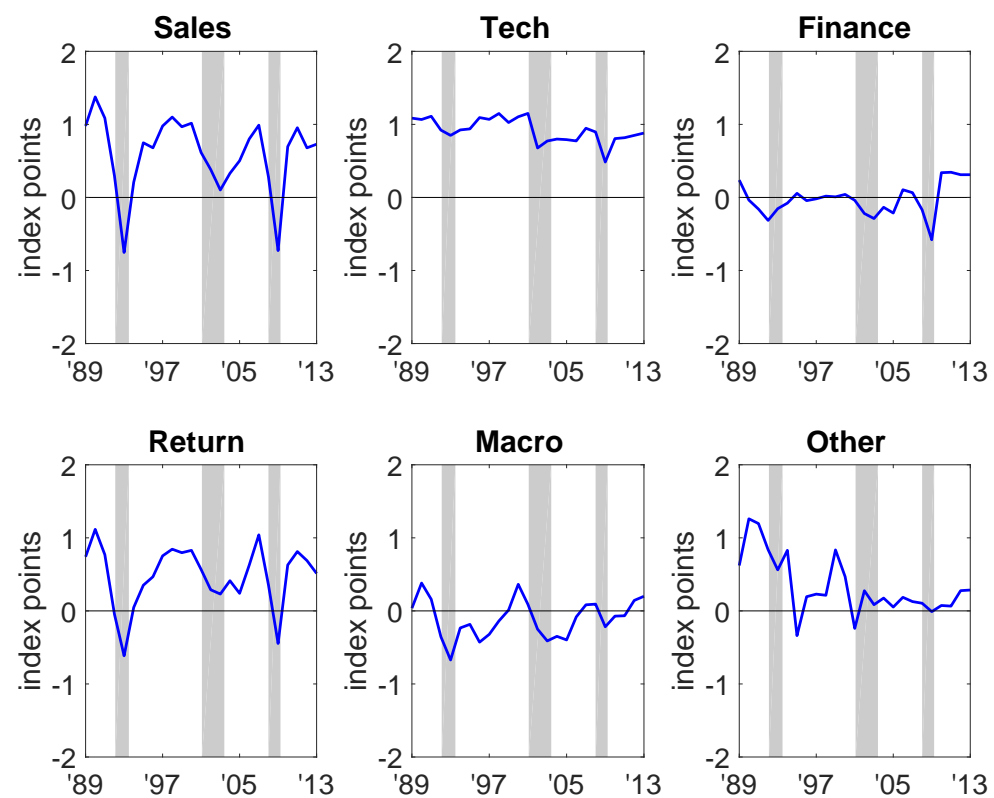

Notes: The panels show the aggregate investment determinant indices Sales, Tech, Finance, Return, Macro, and Other for the West German manufacturing sector, constructed from aggregating the firm-level responses to Q2 with weights as described in the text. Index values above zero represent a positive and index values below zero a negative average effect on aggregate investment activity. The gray-shaded regions show recessions as dated by the Sachverständigenrat (see Sachverständigenrat, 2017 p. 134): 1992:M02 - 1993:M07, 2001:M02 - 2003:M06, 2008:M01 - 2009:M04. 
Figure 3 - Fraction of Survey Respondents in Each Answer Category
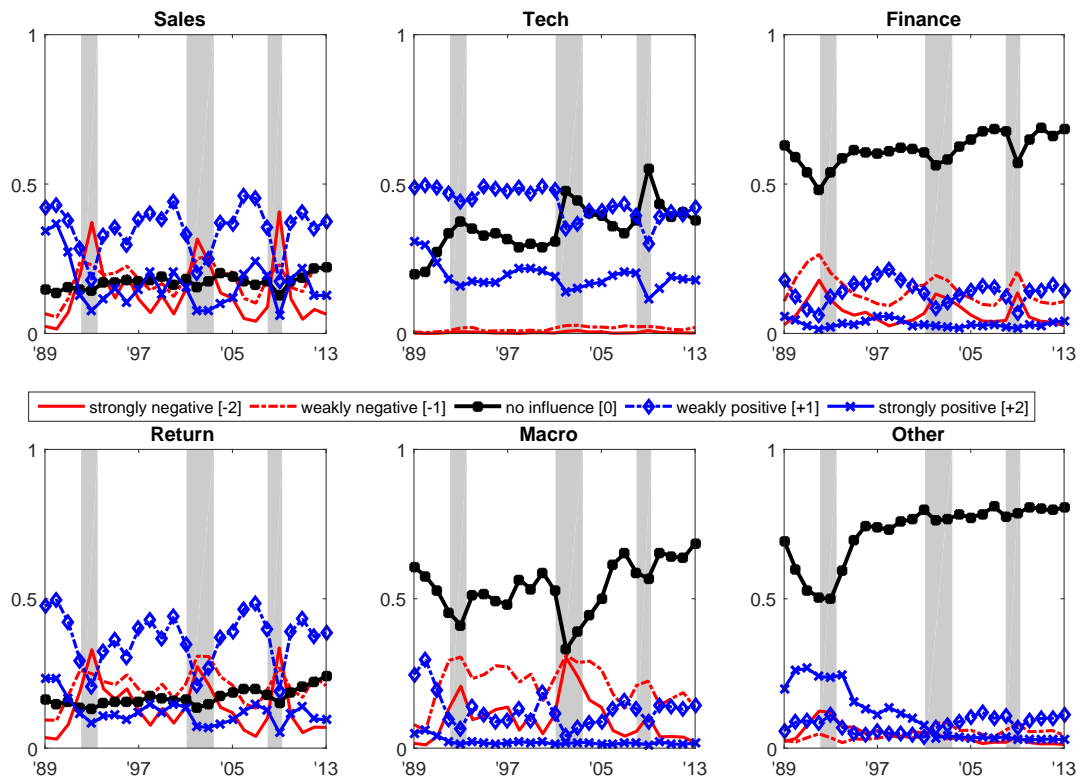

Notes: Each panel of this graph shows the fraction of survey respondents per answer category - "strongly negative", "weakly negative", "no influence", "weakly positive", or "strongly positive" - for each of the six investment determinants: Tech, Sales, Finance, Return, Macro, and Other, referring to the firm-level survey responses in this case. The gray-shaded regions show recessions as dated by the Sachverständigenrat (see Sachverständigenrat 2017, p. 134): 1992:M02 - 1993:M07, 2001:M02 - 2003:M06, 2008:M01 - 2009:M04. 
Figure 4 - Investment Determinant Index Sales, Aggregate Revenues, New Orders and Industrial Production
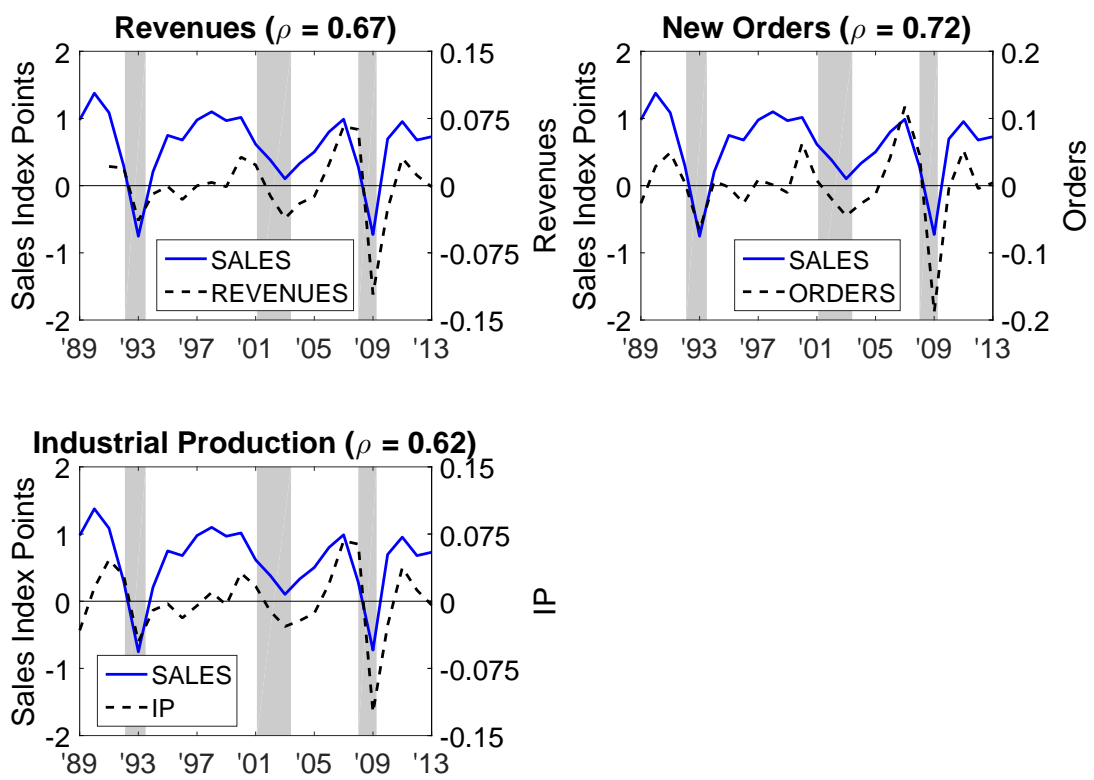

Notes: The top-left panel displays the aggregate investment determinant index Sales, based on Q2, and revenues. $R E V$ ENUES is the cyclical component of the volume index of revenues in the German manufacturing and mining sector, obtained from the Federal Statistical Office and extracted via the HP-filter $(\lambda=6.25)$ after taking the natural logarithm. REVENUES is only available since 1991. The top-right panel compares Sales and new orders. ORDERS is the HP-filtered $(\lambda=6.25)$ series of the natural log of real new orders in the German manufacturing sector, taken from the Bundesbank. The bottom-left panel depicts Sales and industrial production. IP is the volume index of industrial production in the German manufacturing and mining sector at business cycle frequencies, obtained from the Bundesbank and extracted via the HP-filter $(\lambda=6.25)$ after taking the natural logarithm. Values of ORDERS and IP prior to 1991 are based on West German data. The panel titles report the correlation coefficient between the two time series shown, $\rho$. The gray-shaded regions show recessions as dated by the Sachverständigenrat (see Sachverständigenrat 2017, p. 134): 1992:M02 - 1993:M07, 2001:M02 - 2003:M06, 2008:M01 - 2009:M04. 
Figure 5 - Investment Determinant Index Finance, Credit Spreads and Idiosyncratic Firm Uncertainty
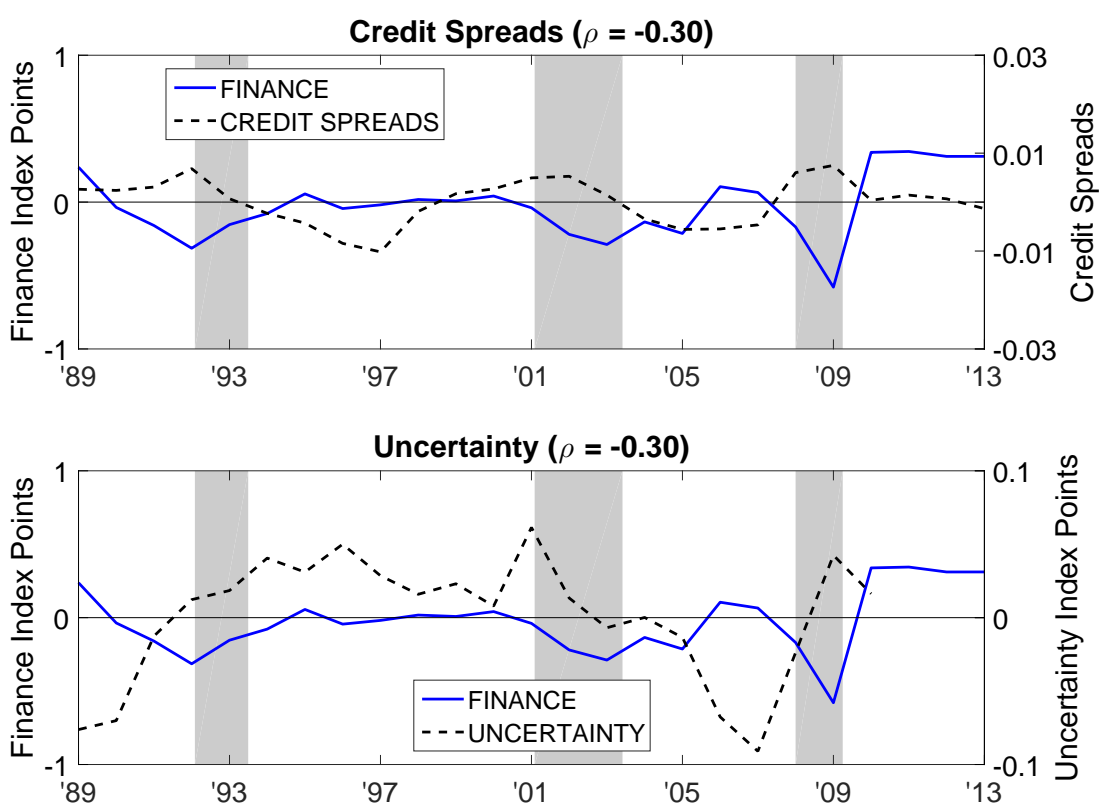

Notes: This figure compares the aggregate investment determinant index Finance, based on Q2, and two covariate candidates. The top panel plots Finance and credit spreads for non-financial corporations. Until 1998, CREDIT SPREADS is the difference between corporate bond yields, obtained from the Bundesbank, and interest rates on 10-year Treasuries, followed by the yearly average of monthly credit spreads for non-financial corporations from Gilchrist and Mojon (2016) since 1999, jointly adjusted for a linear trend. The bottom-panel compares Finance and a measure of idiosyncratic uncertainty in the West German manufacturing sector. UNCERTAINTY is the linearly detrended yearly average of the standard deviation of ex-post forecast errors from Bachmann et al. (2013), which is only available through 2010. The panel titles report the correlation coefficient between the two time series shown, $\rho$. The gray-shaded regions show recessions as dated by the Sachverständigenrat (see Sachverständigenrat 2017, p. 134): 1992:M02 - 1993:M07, 2001:M02 - 2003:M06, 2008:M01 - 2009:M04. 
Figure 6 - Investment Determinant Index Macro and Fiscal Policy Covariate Candidates
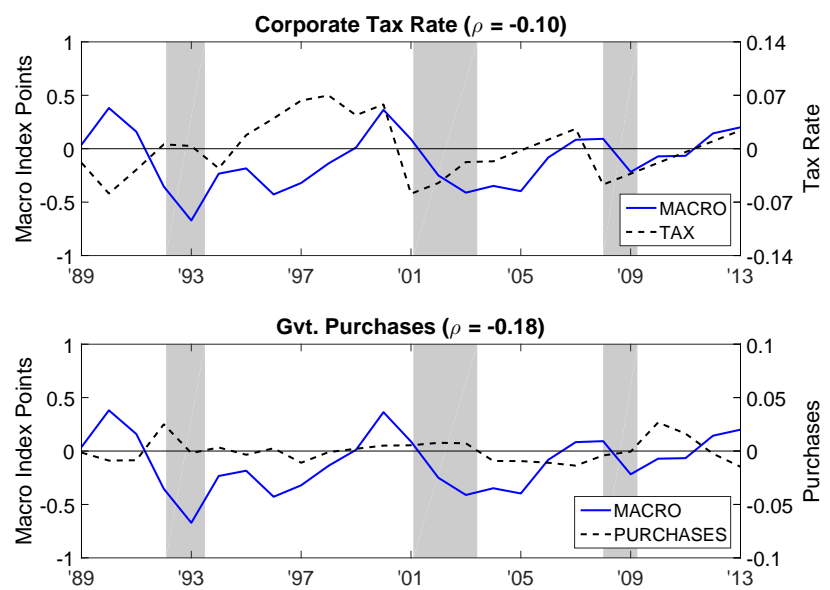

Notes: The top panel compares the aggregate investment determinant index Macro, based on Q2, and TAX, which is the linearly detrended statutory corporate tax rate less deductions obtained from the Organization for Economic Co-operation and Development. The lower panel depicts Macro and government purchases. PURCHASES is the cyclical component of real government purchases (intermediate inputs, wage costs, benefits in kind, and gross investment) from German VGR (Volkswirtschaftliche Gesamtrechnung) data and filtered by means of the HP-filter $(\lambda=6.25)$ after taking the natural logarithm. The panel titles report the correlation coefficient between the two time series shown, $\rho$. Values of TAX and PURCHASES prior to 1991 are based on West German data. The gray-shaded regions show recessions as dated by the Sachverständigenrat (see Sachverständigenrat 2017 p. 134): 1992:M02 - 1993:M07, 2001:M02 - 2003:M06, $2008: M 01$ 2009:M04.

Figure 7 - Investment Determinant Index Macro and Other Covariate Candidates
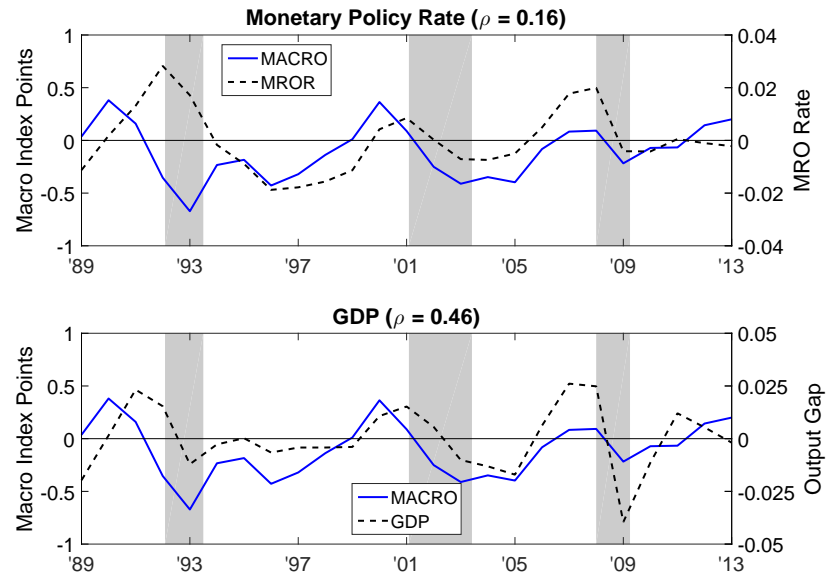

Notes: The top panel compares the aggregate investment determinant index Macro, based on Q2, and the monetary policy rate. MROR (Main Refinancing Operations Rate) is the discount rate set by the Bundesbank until 1998, followed by the main refinancing operations rate set by the European Central Bank since 1999, jointly adjusted for a linear trend. The bottom panel compares Macro and the cyclical component of real gross domestic product, taken from German VGR (Volkswirtschaftliche Gesamtrechnung) data and extracted via the HP-filter $(\lambda=6.25)$ after taking the natural logarithm. Values of GDP prior to 1991 are based on West German data. The panel titles report the correlation coefficient between the two time series shown, $\rho$. The gray-shaded regions show recessions as dated by the Sachverständigenrat (see Sachverständigenrat, 2017 p. 134): 1992:M02 - 1993:M07, 2001:M02 - 2003:M06, 2008:M01 - 2009:M04. 
Figure 8 - Fit and Counterfactual

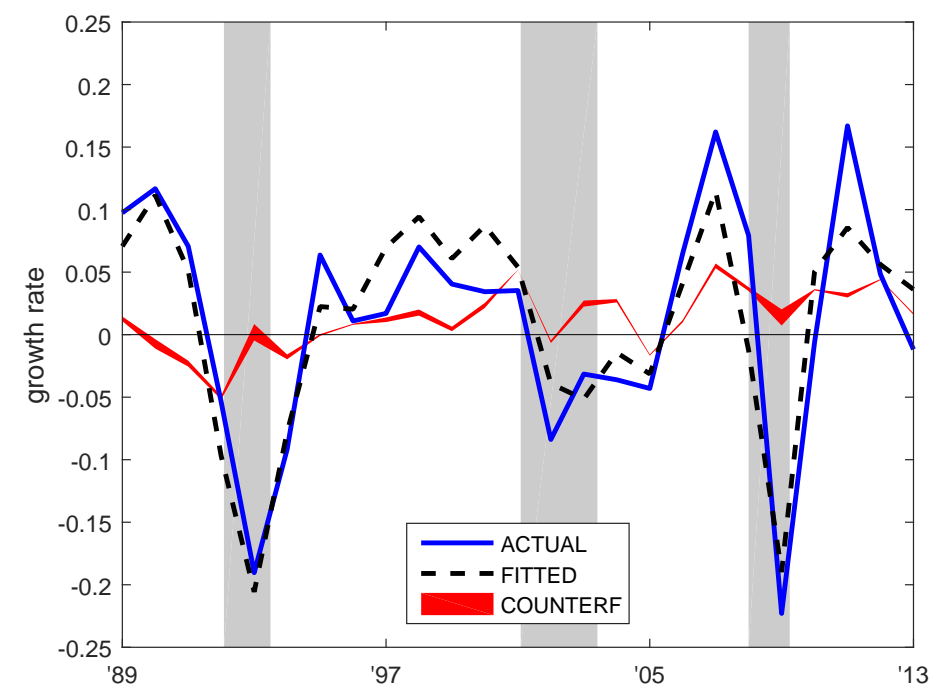

Notes: This figure plots the West German manufacturing investment growth rate obtained from the Federal Statistical Office $\triangle I_{t}^{F S O}, A C T U A L$, the fitted series of the aggregate investment growth rate estimated from equation $(7), F I T T E D$, and the pointwise minima and maxima of the counterfactual fitted series of the aggregate investment growth rate COUNTERF, where the contributions of the set of admissible $\overline{\text { Sales }}$ to the overall fitted series has been subtracted. The gray-shaded regions show recessions as dated by the Sachverständigenrat (see Sachverständigenrat 2017, p. 134): 1992:M02 - 1993:M07, 2001:M02 - 2003:M06, 2008:M01 - 2009:M04. 
Figure 9 - Sales and Sentiment Indicators
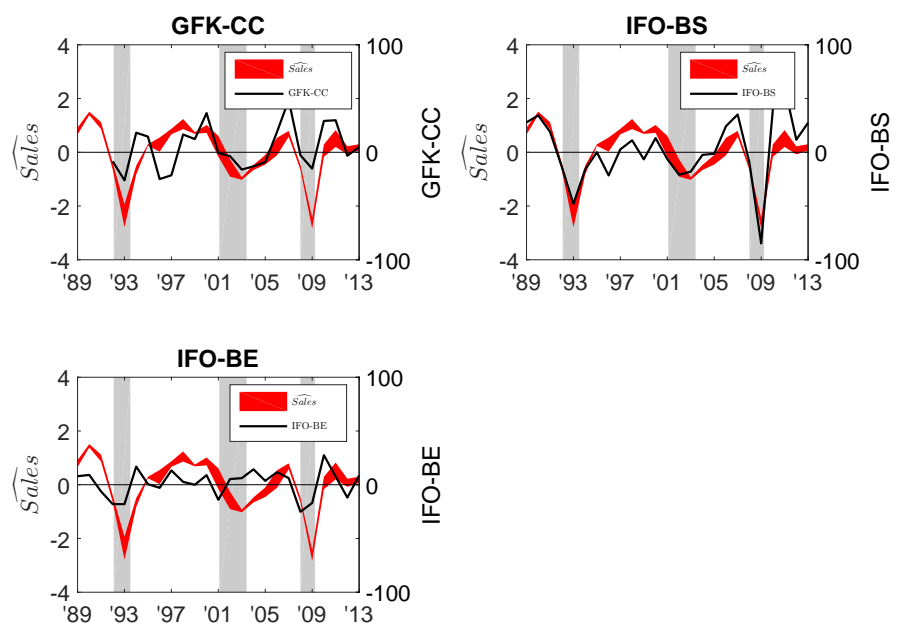

Notes: The figure plots the pointwise minima and maxima of the set of admissible $\overline{\text { Sales }}$ using the baseline identification scheme (left y-axis), along with (right y-axis) the GfK Consumer Confidence Index (GFK-CC), top-left panel, the ifo business situation index for the West German manufacturing sector (IFO-BS), top-right-panel, and the ifo business expectation index (IFO-BE) for the West German manufacturing sector, bottom panel, the latter two from the ifo Business Cycle Survey. The GfK index is only available from 1992. The gray-shaded regions show recessions as dated by the Sachverständigenrat (see Sachverständigenrat 2017 p. 134): 1992:M02 - 1993:M07, 2001:M02 - 2003:M06, 2008 :M01 2009:M04.

Figure 10 - $\overline{\text { Sales }}$ and Policy Variables
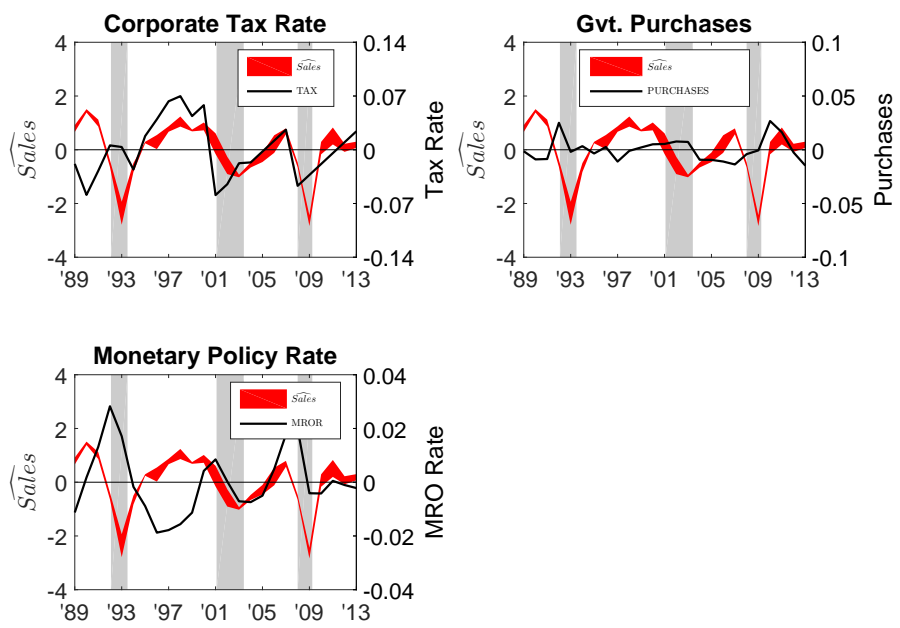

Notes: The figure plots the pointwise minima and maxima of the set of admissible $\overline{\text { Sales }}$ using the baseline identification scheme (left y-axis) against a number of policy variables measuring fiscal and monetary policy (right y-axis). The top-left panel shows the linearly detrended statutory corporate tax rate less deductions obtained from the Organization for Economic Co-operation and Development. The top-right panel depicts the cyclical component of real government purchases (intermediate inputs, wage costs, benefits in kind, and gross investment) from German VGR (Volkswirtschaftliche Gesamtrechnung) data and filtered with the HP-filter $(\lambda=6.25)$ after taking the natural logarithm. The bottom panel shows the discount rate set by the Bundesbank until 1998, followed by the main refinancing operations rate set by the European Central Bank since 1999, jointly adjusted for a linear trend. The gray-shaded regions show recessions as dated by the Sachverständigenrat (see Sachverständigenrat, 2017, p. 134): 1992:M02 - 1993:M07, 2001:M02 - 2003:M06, 2008:M01 - 2009:M04. 
Figure 11 - Impulse Response Functions of a Vector Autoregression in Sales, Tech, $\Delta I_{t}^{F S O}$, and $P P I_{t}$
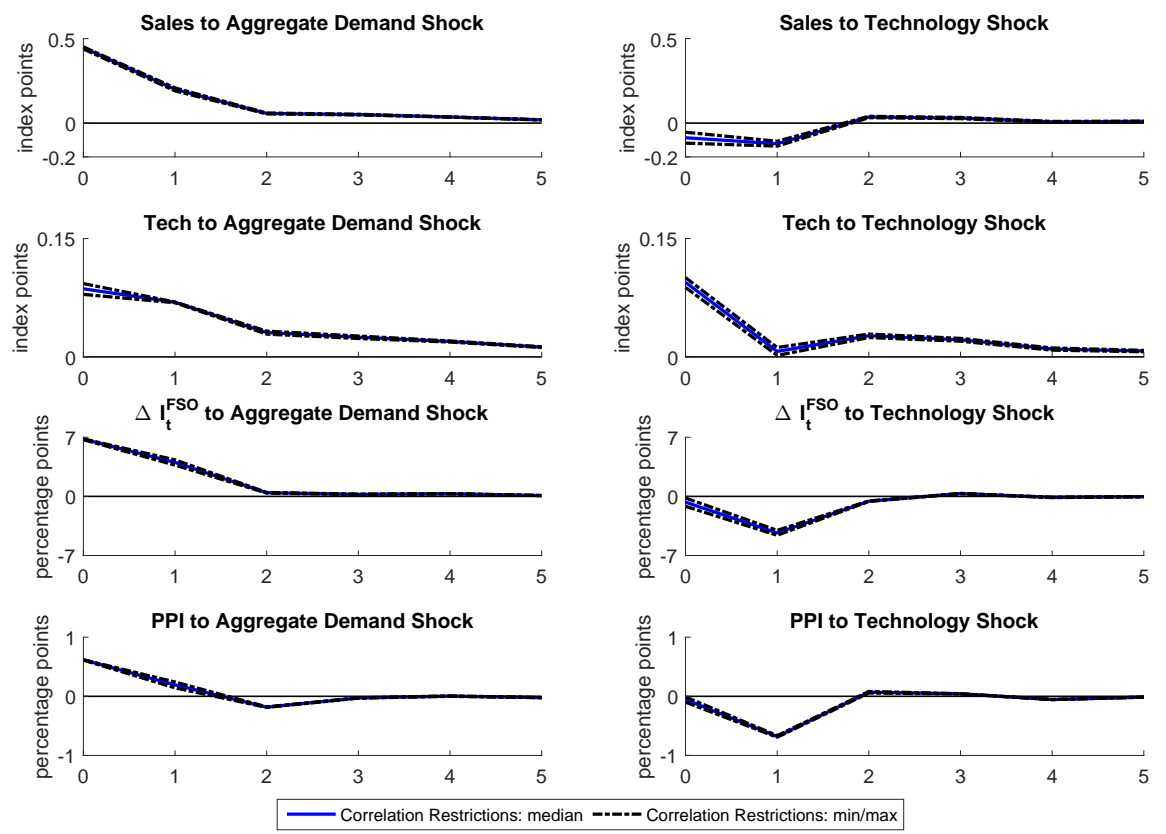

Notes: This figure shows the impulse response functions of a vector autoregression with one lag in the aggregate investment determinant indices Sales, Tech, the aggregate investment growth rate $\left(\Delta I_{t}^{F S O}\right)$, and producer price inflation $\left(P P I_{t}\right)$. Only the identified aggregate demand shocks (left panels) and the identified aggregate technology shocks are depicted (right panels). Shock size is one standard deviation for each shock. The units for Sales and Tech are index points. The units for $\triangle I_{t}^{F S O}$ and $P P I_{t}$ are percentage points. The identification of orthogonal shocks using correlation restrictions follows the procedure described in the text. The solid blue and dashed black lines show, respectively, the impulse response function's pointwise median, minimum, and maximum value from this identification strategy. 
Figure 12 - Contributions of Orthogonalized Shocks to the Variance of $\Delta I_{t}^{F S O}$ at the TwoDigit Industry Level

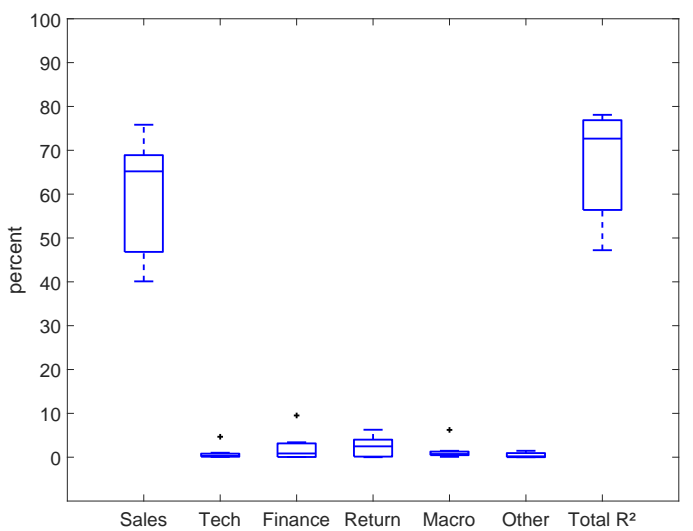

Notes: This figure shows the box-plots of estimates for the variance contributions of shocks to investment fluctuations at the two-digit manufacturing industry level. The estimates are obtained from a variance decomposition in regressions of investment growth on the orthogonalized industry investment determinant indices, $\overline{\operatorname{Sales}_{i}}, \overline{\operatorname{Tech}}_{i}, \overline{\text { Finance }_{i}}, \overline{\operatorname{Return}}_{i}$, $\widehat{\operatorname{Macro}}_{i}$, and $\overline{\mathrm{Dther}}_{i}$, estimated for eight two-digit industries. The industry-specific investment growth rates and investment determinant indices are based on German VGR (Volkswirtschaftliche Gesamtrechnung) data (for 1989 to 1991 we use West German data, and data for all of Germany thereafter) and Q2, respectively. The orthogonal shocks are recovered using the the Choleski-Sales-first identification scheme. The first six box-plots show the contributions of orthogonal shocks to the variance by industry. The final box-plot displays the overall $R^{2}$. The ends of the whiskers represent the lowest and highest estimates from the lowest and highest quartile, respectively, within 1.5 times the interquartile range. Crosses represent estimates outside of that range.

Figure 13 - Contributions of Orthogonalized Shocks to the Variance of $\Delta I_{t}^{F S O}$ at the Laender Level

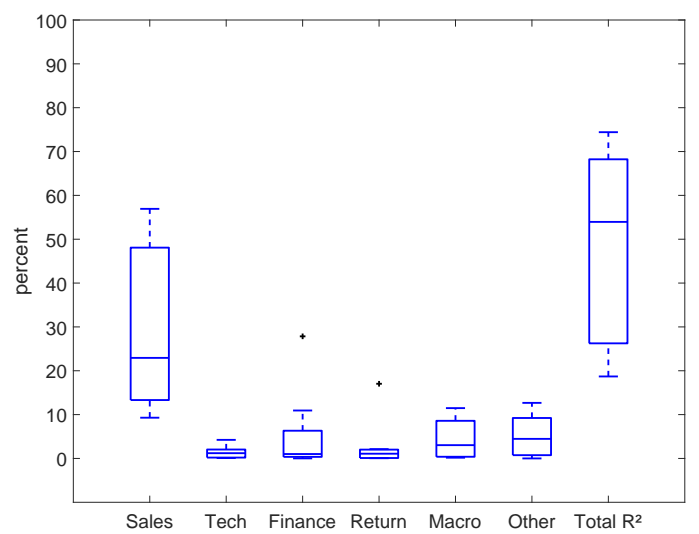

Notes: This figure shows the box-plots of estimates for the contributions of shocks to investment fluctuations at the Laender level. The estimates are obtained from a decomposition of total variance in regressions of investment growth on the orthogonalized Laender investment determinant indices, $\widehat{\operatorname{Tech}}_{i}, \overline{\operatorname{Sales}}_{i}, \overline{\mathrm{Finance}}_{i}, \overline{\operatorname{Return}}_{i}, \overline{\operatorname{Macro}}_{i}$, and $\overline{\mathrm{Dther}}_{i}$, estimated for eight West German Laender. The sample period goes from 1992 to 2008. The Laender-specific investment growth rates and investment determinant indices are based on German VGR (Volkswirtschaftliche Gesamtrechnung) data (only for aggregate, not for manufacturing investment available) and Q2, respectively. The orthogonal shocks are recovered using the the Choleski-Sales-first identification scheme. The first six box-plots show the contributions of orthogonal shocks to the overall variance by Laender. The final box-plot displays the overall $R^{2}$. The ends of the whiskers represent the lowest and highest estimates from the lowest and highest quartile, respectively, within 1.5 times the interquartile range. Outliers are plotted as ' + '. 
Table 1 - Summary Statistics

\begin{tabular}{|c|c|c|c|c|c|c|c|}
\hline & Sales & Tech & Finance & Return & Macro & Other & $\Delta I_{t}^{F S O}$ \\
\hline \multicolumn{8}{|l|}{ Panel A: } \\
\hline Sales & 1 & & & & & & \\
\hline Tech & $0.6640^{* * *}$ & 1 & & & & & \\
\hline Finance & $0.6059^{* * *}$ & $0.3183^{*}$ & 1 & & & & \\
\hline Return & $0.9539^{* * *}$ & $0.5802^{* * *}$ & $0.6165^{* * *}$ & 1 & & & \\
\hline Macro & $0.6381^{* * *}$ & $0.3733^{* *}$ & $0.4481^{* * *}$ & $0.6987^{* * *}$ & 1 & & \\
\hline Other & 0.2228 & $0.3416^{*}$ & -0.0796 & 0.1426 & 0.2538 & 1 & \\
\hline $\begin{array}{l}\text { Panel B: } \\
\Delta I_{t}^{F S O}\end{array}$ & $0.8645^{* * *}$ & $0.5539^{* * *}$ & $0.6191^{* * *}$ & $0.8895^{* * *}$ & $0.6148^{* * *}$ & 0.0346 & 1 \\
\hline \multicolumn{8}{|l|}{ Panel $C$ : } \\
\hline$\hat{\mu}$ & 0.6005 & 0.9193 & -0.0245 & 0.4806 & -0.1046 & 0.3347 & 0.0123 \\
\hline$\hat{\sigma}$ & 0.5155 & 0.1642 & 0.2243 & 0.4192 & 0.2630 & 0.4021 & 0.0943 \\
\hline
\end{tabular}

Notes: Panel A reports the pairwise correlation coefficients between the aggregate investment determinant indices, obtained from aggregating the firm-level responses to Q2 with weights as described in the text. Panel B shows the correlations of the aggregate investment determinant indices with the aggregate investment growth rate in the West German manufacturing and mining sector, $\Delta I_{t}^{F S O}$. Up to and including $2011, \Delta I_{t}^{F S O}$ is administrative data provided by the Federal Statistical Office. From 2012 onwards, $\Delta I_{t}^{F S O}$ is administrative aggregate investment growth data in the manufacturing and mining sector of unified Germany. Significance at the $1 \%, 5 \%$, and $10 \%$ level is indicated by ***, ${ }^{* *}$, and * , respectively. The statistical significance levels are based on a moving-block bootstrap with overlapping blocks of 3 years length and 10,000 replications, where we compute the fraction of bootstrap samples for which the correlation coefficient equals zero or has opposite sign of the point estimate. Panel C contains the sample means and the sample standard deviations of the aggregate investment determinant indices and the aggregate investment growth rate.

Table 2 - Mean of Tech Conditional on Maintenance Investment

\begin{tabular}{lcc}
\hline Tercile of Fraction of Maintenance Investment & Mean(Tech) & N \\
\hline less or equal 24\% & 0.9901 & 12751 \\
between $24 \%$ and $50 \%$ & 0.8198 & 13855 \\
more or equal 50\% & 0.6819 & 11520 \\
\hline
\end{tabular}

Notes: This table displays the conditional mean of the investment determinant index Tech, which is based on Q2, across firm-year observations. The mean uses the weights as described in the text and is conditional on the terciles of the shares of maintenance investment as a fraction of total investment for a given firm-year, computed from the ifo Investment Survey. Differences in conditional means between any two terciles are statistically significant at the $1 \%$ level, based on a one-sided $t$ test. The non-uniform distribution of observations across terciles is due to data bunching at the tercile boundaries. 
Table 3 - Mean of Tech Conditional on Investment in Restructuring and Rationalization

\begin{tabular}{lcc}
\hline Tercile of Fraction of Restructuring and Rationalization Investment & Mean(Tech) & $\mathrm{N}$ \\
\hline less or equal $20 \%$ & 0.7640 & 16403 \\
between $20 \%$ and $40 \%$ & 0.9285 & 9069 \\
more or equal $40 \%$ & 1.0657 & 12654 \\
\hline
\end{tabular}

Notes: This table displays the conditional mean of the investment determinant index Tech, which is based on Q2, across firm-year observations. The mean uses the weights as described in the text and is conditional on the terciles of the shares of restructuring and rationalization investment as a fraction of total investment for a given firm-year, computed from the ifo Investment Survey. Differences in conditional means between any two terciles are statistically significant at the $1 \%$ level, based on a one-sided $t$ test. The non-uniform distribution of observations across terciles is due to data bunching at the tercile boundaries.

Table 4 - Mean of Tech Conditional on Process Innovation

\begin{tabular}{ccc}
\hline Process Innovation & Mean $($ Tech $)$ & N \\
\hline No & 0.9482 & 13078 \\
Yes & 1.0825 & 5430 \\
\hline
\end{tabular}

Notes: This table displays the conditional mean of the investment determinant index Tech, which is based on Q2, across firm-year observations. The mean uses the weights as described in the text and is conditional on whether capital expenditures also aimed at process innovation, computed from the ifo Investment Survey. The corresponding question was asked in the spring questionnaire about capital expenditures from the previous year, from 1989 until the year 2001. Differences in conditional means between Yes and No answers are statistically significant at the $1 \%$ level, based on a one-sided $t$ test.

Table 5 - Mean of $\mid$ Tech| Conditional on Eurostat's Technology Classification

\begin{tabular}{lcc}
\hline Eurostat's Technology Classification & Mean $(\mid$ Tech $\mid)$ & $\mathrm{N}$ \\
\hline Low-technology & 0.9057 & 14254 \\
Medium-technology & 0.9105 & 11485 \\
High-technology & 0.9335 & 11995 \\
\hline
\end{tabular}

Notes: This table displays the conditional mean of the absolute value of the investment determinant index Tech, which is based on Q2, across firm-year observations. The mean uses the weights as described in the text and is conditional on Eurostat's technology classifications, which groups together manufacturing industries according to their technological intensity, defined as the ratio of industry R\&D spending to value added. Because of the industry classifications available at the ifo, we find it convenient to group Eurostat's medium-high-technology and high-technology industries together into one high-technology category, while Eurostat's medium-low-technology industries are labeled here simply as the mediumtechnology category. Differences in means between any two technology industries are statistically significant at the $1 \%$ level, based on a one-sided $t$ test, except for the difference between low-technology industries and medium-technology industries, which is statistically insignificant. 
Table 6 - Mean of |Finance| Conditional on External Finance Dependence

\begin{tabular}{lcc}
\hline Tercile of Fraction of External Finance & Mean $(\mid$ Finance $\mid)$ & $\mathrm{N}$ \\
\hline exactly 0\% & 0.2299 & 10597 \\
between 0\% and 20\% & 0.4193 & 1280 \\
more or equal 20\% & 0.5080 & 5525 \\
\hline
\end{tabular}

Notes: This table displays the conditional mean of the absolute value of the investment determinant index Finance, which is based on Q2, across firm-year observations. The mean uses the weights as described in the text and is conditional on the share of external finance raised for capital expenditures, computed from the ifo Investment Survey. The corresponding question was asked in the spring questionnaire about capital expenditures from the previous year, from 1989 until the year 2001. Differences in conditional means between any two external finance dependence terciles are statistically significant at the $1 \%$ level, based on a one-sided $t$ test. The non-uniform distribution of observations across terciles is due to data bunching at the tercile boundaries.

Table 7 - Investment Determinants and Their Relation to Price-Setting Behavior of Firms

\begin{tabular}{|c|c|c|c|c|c|c|c|c|}
\hline & \multicolumn{8}{|c|}{ LHS Variable is... } \\
\hline & \multicolumn{4}{|c|}{ Frequency of Price Increases } & \multicolumn{4}{|c|}{ Frequency of Price Decreases } \\
\hline & $(1)$ & $(2)$ & $(3)$ & $(4)$ & $(5)$ & (6) & $(7)$ & $(8)$ \\
\hline Sales & $\begin{array}{l}0.015^{* * *} \\
(0.0015)\end{array}$ & $\begin{array}{l}0.0069^{* * *} \\
(0.0015)\end{array}$ & $\begin{array}{l}0.0073^{* * *} \\
(0.0015)\end{array}$ & $\begin{array}{l}0.0091^{* * *} \\
(0.0014)\end{array}$ & $\begin{array}{l}-0.023^{* * *} \\
(0.0020)\end{array}$ & $\begin{array}{l}-0.016^{* * *} \\
(0.0021)\end{array}$ & $\begin{array}{l}-0.015^{* * *} \\
(0.0019)\end{array}$ & $\begin{array}{l}-0.014^{* * *} \\
(0.0016)\end{array}$ \\
\hline Tech & $\begin{array}{l}-0.0086^{* * *} \\
(0.0030)\end{array}$ & $\begin{array}{l}-0.0076^{\text {***}} \\
(0.0029)\end{array}$ & $\begin{array}{l}-0.0088^{\text {*** }} \\
(0.0028)\end{array}$ & $\begin{array}{l}-0.0085^{* * *} \\
(0.0025)\end{array}$ & $\begin{array}{l}0.0054^{* *} \\
(0.0027)\end{array}$ & $\begin{array}{l}0.0069^{* *} \\
(0.0027)\end{array}$ & $\begin{array}{c}0.0036 \\
(0.0026)\end{array}$ & $\begin{array}{c}0.00041 \\
(0.0023)\end{array}$ \\
\hline Constant & $\begin{array}{l}0.096^{* * *} \\
(0.0039)\end{array}$ & $\begin{array}{c}0.14^{* * *} \\
(0.0081)\end{array}$ & $\begin{array}{l}0.13^{* * *} \\
(0.021)\end{array}$ & $\begin{array}{c}0.14^{* * *} \\
(0.0074)\end{array}$ & $\begin{array}{l}0.076^{* * *} \\
(0.0042)\end{array}$ & $\begin{array}{l}0.025^{* * *} \\
(0.0042)\end{array}$ & $\begin{array}{c}0.032 \\
(0.030)\end{array}$ & $\begin{array}{l}0.025^{* * *} \\
(0.0051)\end{array}$ \\
\hline Observations & 11539 & 11539 & 11520 & 11539 & 11539 & 11539 & 11520 & 11539 \\
\hline$R^{2}$ & 0.013 & 0.061 & 0.079 & 0.072 & 0.028 & 0.051 & 0.082 & 0.073 \\
\hline Year Effects & No & Yes & Yes & Yes & No & Yes & Yes & Yes \\
\hline Firm Fixed Effects & No & No & No & Yes & No & No & No & Yes \\
\hline Industry Effects & No & No & Yes & No & No & No & Yes & No \\
\hline
\end{tabular}

Notes: This table reports Ordinary Least Squares (OLS) estimates from linear regressions of the frequency of price change on Sales, Tech, and a constant. Here Sales and Tech are the firm-level survey responses to Q2. For each firm Price Increases is the frequency of price increases in a given year, defined as the yearly mean of the employment-weighted average of a monthly product-level price increase dummy variable constructed from the ifo Business Cycle Survey. The definition of Price Decreases is analogous. Industry Effects are at the two-digit industry level. The sample comprises a subset of firms in the ifo Investment Survey for which we can merge data from the ifo Business Cycle Survey. Significance at the $1 \%, 5 \%$, and $10 \%$ level is indicated by ${ }^{* *},{ }^{* *}$, and ${ }^{*}$, respectively. Standard errors in parentheses are clustered at the firm level. 
Table 8 - Contribution to the Variance of $\Delta I_{t}^{F S O}$ (in percent)

\begin{tabular}{|c|c|c|c|}
\hline & Correlation Restrictions & Recursive: Sales first & Recursive: Tech first \\
\hline \multicolumn{4}{|l|}{ Panel A: } \\
\hline$\overline{\text { Sales }}$ & {$[65.92,74.81]$} & 74.74 & 44.13 \\
\hline$\widehat{\mathrm{Tech}}$ & {$[0.00,8.89]$} & 0.07 & 30.68 \\
\hline Finance & 1.37 & 1.37 & 1.37 \\
\hline$\overline{\text { Return }}$ & 4.08 & 4.08 & 4.08 \\
\hline$\overline{\text { Macro }}$ & 0.00 & 0.00 & 0.00 \\
\hline$\overline{\text { Other }}$ & 1.15 & 1.15 & 1.15 \\
\hline$R^{2}$ of equation 7 & 0.81 & 0.81 & 0.81 \\
\hline \multicolumn{4}{|l|}{ Panel B: } \\
\hline Corr ( $\overline{\text { Sales }}$, Sales $)$ & {$[0.95,1.00]$} & 1.00 & 0.75 \\
\hline $\operatorname{Corr}(\widehat{T e c h}, T e c h)$ & {$[0.50,0.81]$} & 0.75 & 1.00 \\
\hline Corr $(\overline{\text { Sales }}$, PPI $)$ & {$[0.47,0.52]$} & 0.51 & 0.42 \\
\hline $\operatorname{Corr}(\overline{\text { Tech }}, \mathrm{PPI})$ & {$[-0.22,-0.01]$} & -0.06 & 0.30 \\
\hline
\end{tabular}

Notes: Panel A of this table reports the variance contributions of the orthogonal shocks to aggregate investment growth fluctuations in the West German manufacturing and mining sector. The estimates are obtained from a variance decomposition in a regression of investment growth, $\Delta I_{t}^{F S O}$, on admissible orthogonal shocks (equation (7)). The aggregate investment growth rate is obtained from the Federal Statistical Office. The identification of orthogonal shocks from the investment determinant indices, based on Q2, follows the procedure described in the text. The first column shows (the range of) results for the set of admissible solutions for the orthogonal shocks, resulting from our baseline correlation-based identification scheme that combines a narrative approach with basic aggregate demand and supply theory on prices. The second column shows results for one particular solution from this set which corresponds to a Cholesky decomposition with Sales ordered first. The third column shows results for a Cholesky decomposition with Tech ordered first, which is not contained in the set. Panel B shows the correlations between $\overline{\text { Sales }}$ and Sales, and $\overline{\mathrm{Tech}}$ and Tech, the range of correlations our narrative identification assumptions span. It also shows the resulting correlations between Sales and Tech with PPI Inflation. PPI Inflation is the yearly rate of change in the producer price index of the German manufacturing sector. 
Table 9 - Contribution to the Variance of $\Delta I_{t}^{F S O}$ (in percent): Sensitivity Analysis

\begin{tabular}{|c|c|c|c|}
\hline & Low Narrative Correlations & High Narrative Correlations & Deflated Specification \\
\hline \multicolumn{4}{|l|}{ Panel A: } \\
\hline$\overline{\text { Sales }}$ & {$[49.39,74.81]$} & {$[74.45,74.81]$} & {$[65.11,74.88]$} \\
\hline$\widehat{\text { Tech }}$ & {$[0.00,25.42]$} & {$[0.00,0.36]$} & {$[0.00,9.77]$} \\
\hline Finance & 1.37 & 1.37 & 1.37 \\
\hline$\widehat{\text { Return }}$ & 4.08 & 4.08 & 4.76 \\
\hline$\overline{\text { Macro }}$ & 0.00 & 0.00 & 0.23 \\
\hline$\overline{\text { Other }}$ & 1.15 & 1.15 & 2.63 \\
\hline$R^{2}$ of equation 7 & 0.81 & 0.81 & 0.84 \\
\hline \multicolumn{4}{|l|}{ Panel B: } \\
\hline $\operatorname{Corr}(\overline{\text { Sales }}$, Sales $)$ & {$[0.83,1.00]$} & {$[0.99,1.00]$} & {$[0.95,1.00]$} \\
\hline $\operatorname{Corr}(\overline{\mathrm{Tech}}, \mathrm{Tech})$ & {$[0.25,0.81]$} & {$[0.75,0.81]$} & {$[0.50,0.81]$} \\
\hline Corr $(\overline{\text { Sales }}, \mathrm{PPI})$ & {$[0.39,0.52]$} & {$[0.51,0.52]$} & {$[0.47,0.52]$} \\
\hline $\operatorname{Corr}(\widehat{\text { Tech }}, \mathrm{PPI})$ & {$[-0.33,-0.01]$} & {$[-0.06,-0.01]$} & {$[-0.22,-0.01]$} \\
\hline \multicolumn{4}{|c|}{$\begin{array}{l}\text { Notes: This table investigates the sensitivity of the results reported in the first column of Table } 8 \text { The first column of this } \\
\text { tables sets the threshold value for the narrative correlations of Sales with Sales and Tech with Tech in the identification } \\
\text { strategy to } 0.25 \text { instead of } 0.5 \text {, while the second column sets the threshold value to } 0.75 \text {. The third column deflates } \\
\text { aggregate investment growth by the deflator for gross fixed capital formation in the manufacturing sector, obtained from } \\
\text { German VGR (Volkswirtschaftliche Gesamtrechnung), where values prior to } 1991 \text { are based on West German data. The } \\
\text { correlations in panel B, third column are, by construction, the same as in the first column of Table } 8 \text { See the notes to } \\
\text { Table } 8 \text { for further information. }\end{array}$} \\
\hline
\end{tabular}

Table 10 - Inter-Industry Effects

\begin{tabular}{|c|c|c|c|c|c|c|c|c|}
\hline & $\begin{array}{l}\text { Coal, } \\
\text { Chemicals, } \\
\text { Petroleum }\end{array}$ & $\begin{array}{l}\text { Rubber, } \\
\text { Plastics }\end{array}$ & $\begin{array}{l}\text { Glass, } \\
\text { Ceramics, } \\
\text { Stone }\end{array}$ & $\begin{array}{l}\text { Metal } \\
\text { Production } \\
\text { and } \\
\text { Processing }\end{array}$ & $\begin{array}{l}\text { Machines, } \\
\text { Cars, Other } \\
\text { Heavy } \\
\text { Manufacturing }\end{array}$ & $\begin{array}{l}\text { Wood, } \\
\text { Paper, } \\
\text { Printing } \\
\text { g }\end{array}$ & $\begin{array}{l}\text { Textile, } \\
\text { Leather }\end{array}$ & $\begin{array}{l}\text { Food, } \\
\text { Tobacco }\end{array}$ \\
\hline \multicolumn{9}{|c|}{ Panel A: Upstream Channel } \\
\hline & 0.0330 & -0.0870 & -0.0140 & -0.2383 & 0.0570 & 0.1075 & 0.1700 & 0.3145 \\
\hline std. error & 0.2123 & 0.1755 & 0.2236 & 0.3170 & 0.2242 & 0.2350 & 0.2977 & 0.1660 \\
\hline$R^{2}$ & 0.0014 & 0.0085 & 0.0002 & 0.0697 & 0.0037 & 0.0135 & 0.0334 & 0.1195 \\
\hline \multicolumn{9}{|c|}{ Panel B: Downstream Channel } \\
\hline$\beta$ & -0.0734 & 0.0432 & -0.0319 & 0.1255 & -0.0560 & 0.0428 & -0.2791 & 0.3600 \\
\hline std. error & 0.1549 & 0.2253 & 0.1458 & 0.2146 & 0.2058 & 0.2018 & 0.2195 & 0.3128 \\
\hline$R^{2}$ & 0.0165 & 0.0029 & 0.0025 & 0.0183 & 0.0091 & 0.0042 & 0.1020 & 0.1342 \\
\hline Share in Percent & 16.0427 & 3.6413 & 3.1055 & 9.0785 & 54.7607 & 5.2995 & 1.3092 & 6.7626 \\
\hline \multicolumn{9}{|c|}{$\begin{array}{l}\text { Notes: For each two-digit manufacturing industry in the ifo Investment Survey (we leave out 'Mining' for this exercise) } \\
\text { panel A of the table reports ordinary least squares (OLS) estimates for regressions of an upstream index, USI }{ }_{t}^{i} \text {, on industry- } \\
\text { level technology shocks, } \overline{T e c h}_{i t} \text {. The upstream index is the input-weighted average of demand shocks in all other two-digit } \\
\text { industries, as defined in equation } 5 . \text {. Panel B of the table reports OLS estimates for regressions of a downstream index, } \\
\mathrm{DSI}_{t}^{i} \text {, on industry-level demand shocks, Sales } i t \text {. The downstream index is the output-weighted average of technology shocks } \\
\text { in all other two-digit industries, as defined in equation } 10 . \text { All orthogonal shocks here are identified through the Choleski- } \\
\text { Sales-first identification scheme. The last row shows the time series average of the nominal investment expenditures per } \\
\text { manufacturing subsector as a fraction of total nominal investment expenditures in German manufacturing. }\end{array}$} \\
\hline
\end{tabular}


Table 11 - Contribution to the Variance of $\Delta I P_{t}$

\begin{tabular}{lc}
\hline & $\Delta I P_{t}$ \\
\hline$\overline{\text { Sales }}$ & {$[50.32,62.91]$} \\
$\overline{\text { Tech }}$ & {$[0.12,12.72]$} \\
F⿳亠口冋ance & 5.50 \\
Return & 0.04 \\
$\overline{\text { Macro }}$ & 4.25 \\
$\overline{\text { Other }}$ & 0.31 \\
\hline$R^{2}$ & 0.73
\end{tabular}

Notes: This table reports the range of variance contributions of the admissible orthogonal aggregate shocks from our baseline identification scheme to aggregate industrial production growth fluctuations in the German manufacturing sector. $\Delta I P_{t}$ is the growth rate of the yearly average of monthly industrial production data in levels for the German manufacturing and mining sector obtained from the Bundesbank.

Table 12 - Five-year Forecast Error Variance Decomposition for a Vector Autoregression in Tech, Sales, $\triangle I_{t}^{F S O}$, and $P P I_{t}$

\begin{tabular}{|c|c|c|c|c|c|c|}
\hline \multirow[t]{3}{*}{ Panel A: } & \multicolumn{6}{|c|}{ Contribution of... } \\
\hline & \multicolumn{3}{|c|}{ Aggregate Demand Shocks } & \multicolumn{3}{|c|}{ Technology Shocks } \\
\hline & Corr. Restrictions & Sales first & Tech first & Corr. Restrictions & Sales first & Tech first \\
\hline$\Delta I_{t}^{F S O}$ & {$[56.48,62.63]$} & 66.26 & 62.36 & {$[15.92,22.07]$} & 12.29 & 16.19 \\
\hline$P P I_{t}$ & {$[15.55,17.43]$} & 18.96 & 23.36 & {$[16.37,18.25]$} & 14.84 & 10.44 \\
\hline \multirow[t]{2}{*}{ Panel B: } & \multirow{2}{*}{\multicolumn{2}{|c|}{ Correlation Restrictions }} & \multirow{2}{*}{\multicolumn{2}{|c|}{ Recursive: Sales first }} & \multirow{2}{*}{\multicolumn{2}{|c|}{ Recursive: Tech first }} \\
\hline & & & & & & \\
\hline $\operatorname{Corr}(\overline{\text { Sales }}, \mathrm{PPI})$ & \multicolumn{2}{|c|}{$[0.37,0.37]$} & \multicolumn{2}{|r|}{0.37} & \multicolumn{2}{|c|}{0.30} \\
\hline $\operatorname{Corr}(\widehat{\operatorname{Tech}}, \mathrm{PPI})$ & \multicolumn{2}{|c|}{$[-0.06,-0.01]$} & \multicolumn{2}{|r|}{0.04} & \multicolumn{2}{|c|}{0.23} \\
\hline $\operatorname{Corr}(\widehat{\text { Sales }}$, Sales $)$ & \multicolumn{2}{|c|}{$[0.79,0.81]$} & \multicolumn{2}{|r|}{0.81} & \multicolumn{2}{|c|}{0.69} \\
\hline $\operatorname{Corr}(\widehat{\operatorname{Tech}}, \mathrm{Tech})$ & \multicolumn{2}{|c|}{$[0.50,0.57]$} & \multicolumn{2}{|r|}{0.62} & \multicolumn{2}{|c|}{0.73} \\
\hline \multicolumn{7}{|c|}{$\begin{array}{l}\text { Notes: Panel A of this table reports the five-year forecast error variance decomposition of a vector autoregression with } \\
\text { one lag in the aggregate investment determinant indices Sales, Tech, the aggregate investment growth rate }\left(\Delta I_{t}^{F S O}\right) \text {, and } \\
\text { producer price inflation }\left(P P I_{t}\right) \text {. The identification of orthogonal shocks using correlation restrictions follows the procedure } \\
\text { described in the text (first and fourth column). The second and fifth columns show results using a the Choleski-Sales-first } \\
\text { identification scheme. The third and sixth columns show results using a the Choleski-Tech-first identification scheme. Panel } \\
\text { B shows results from the same vector autoregression as in panel A, specifically, the correlations between Sales and Sales, } \\
\text { and Tech and Tech, the range of correlations our narrative identification assumptions span. It also shows the resulting } \\
\text { correlations between Sales and Tech with PPI Inflation. }\end{array}$} \\
\hline
\end{tabular}


Table 13 - Weighted Average of the Contribution to the Variance of $\Delta I_{t}^{F S O}$ (in percent) at the Two-Digit Industry Level and at the Laender Level

\begin{tabular}{lcc}
\hline Level & 2-digit Industry & Laender \\
\hline$\overline{\text { Sales }}$ & 61.46 & 41.01 \\
$\overline{\text { Tech }}$ & 0.52 & 2.06 \\
Finance & 1.68 & 3.60 \\
$\overline{\text { Return }}$ & 3.36 & 2.57 \\
$\overline{\text { Macro }}$ & 1.24 & 4.48 \\
$\overline{\text { Dther }}$ & 0.76 & 6.69 \\
\hline$R^{2}$ & 0.69 & 0.60 \\
\hline
\end{tabular}

Notes: This table reports the investment-weighted average of the variance contributions of orthogonal shocks to investment fluctuations (and the total $R^{2}$ ) at the two-digit manufacturing industry level and at the Laender level. All orthogonal shocks here are identified through the Choleski-Sales-first identification scheme. See the notes to Figures 12 and 13 for further information. 


\section{Appendix: Survey Guidelines (Translated)}

The ifo Investment Survey gives the following guidelines (translated by us into English) on the firm-level investment determinants to complete Q2 of the survey questionnaire:

Sales Situation and Expectation To be considered are aspects like the degree of capacity utilization, the expected range of price movements and changes in sales figures, and an assessment of the uncertainty surrounding these expectations.

Finance This counts factors like disposable financial resources, borrowing costs, and interest rate expectations.

Return Expectation To be considered are factors like the return on investment and the relative attractiveness of fixed assets and financial assets.

Technological Factors This comprises all incentives to invest which come from technological development.

Macro Policy Environment To be considered are aspects such as an assessment of the effects of economic policy, the tax regulations applying to investment, as well as the possibility to outsource production abroad. 